\title{
Evaluating the adaptive evolutionary convergence of carnivorous plant taxa through functional genomics
}

\author{
Gregory L Wheeler Corresp., ${ }^{1}$, Bryan C Carstens ${ }^{1}$ \\ ${ }^{1}$ Department of Evolution, Ecology, \& Organismal Biology, The Ohio State University, Columbus, Ohio, United States \\ Corresponding Author: Gregory L Wheeler \\ Email address: wheeler.1008@osu.edu
}

Carnivorous plants are striking examples of evolutionary convergence, displaying complex and often highly similar adaptations despite lack of shared ancestry. Using available carnivorous plant genomes along with non-carnivorous reference taxa, this study examines the convergence of functional overrepresentation of genes previously implicated in plant carnivory. Gene Ontology (GO) coding was used to quantitatively score functional representation in these taxa, in terms of proportion of carnivory-associated functions relative to all functional sequence. Statistical analysis revealed that, in carnivorous plants as a group, only two of the 24 functions tested showed a signal of substantial overrepresentation. However, when the four carnivorous taxa were analyzed individually, 11 functions were found to be significant in at least one taxon. Though carnivorous plants collectively may show overrepresentation in functions from the predicted set, the specific functions that are overrepresented vary substantially from taxon to taxon. While it is possible that some functions serve a similar practical purpose such that one taxon does not need to utilize both to achieve the same result, it appears that there are multiple approaches for the evolution of carnivorous function in plant genomes. Our approach could be applied to tests of functional convergence in other systems provided on the availability of genomes and annotation data for a group. 
1 Title: Evaluating the adaptive evolutionary convergence of carnivorous plant taxa through

2 functional genomics

3 Gregory L. Wheeler ${ }^{1 *}$ and Bryan C. Carstens ${ }^{1}$

$4 \quad{ }^{1}$ Department of Evolution, Ecology, \& Organismal Biology, The Ohio State University, 318 W.

$512^{\text {th }}$ Avenue, 300 Aronoff Lab, Columbus, OH 43210-1293, USA.

6 Running Head: Carnivorous plant functional convergence

7 Corresponding Author: Gregory L. Wheeler, Department of Evolution, Ecology, \& Organismal

8 Biology, The Ohio State University, 318 W. $12^{\text {th }}$ Avenue, 300 Aronoff Lab, Columbus, OH

9 43210-1293, USA.

10 Correspondence: gwheeler.eb@gmail.com, wheeler.1008@osu.edu

11 ABSTRACT

12 Carnivorous plants are striking examples of evolutionary convergence, displaying complex and

13 often highly similar adaptations despite lack of shared ancestry. Using available carnivorous plant 
14 genomes along with non-carnivorous reference taxa, this study examines the convergence of

15 functional overrepresentation of genes previously implicated in plant carnivory. Gene Ontology

16 (GO) coding was used to quantitatively score functional representation in these taxa, in terms of

17 proportion of carnivory-associated functions relative to all functional sequence. Statistical

18 analysis revealed that, in carnivorous plants as a group, only two of the 24 functions tested

19 showed a signal of substantial overrepresentation. However, when the four carnivorous taxa were

20 analyzed individually, 11 functions were found to be significant in at least one taxon. Though

21 carnivorous plants collectively may show overrepresentation in functions from the predicted set,

22 the specific functions that are overrepresented vary substantially from taxon to taxon. While it is

23 possible that some functions serve a similar practical purpose such that one taxon does not need

24 to utilize both to achieve the same result, it appears that there are multiple approaches for the

25 evolution of carnivorous function in plant genomes. Our approach could be applied to tests of

26 functional convergence in other systems provided on the availability of genomes and annotation

27 data for a group. 


\section{INTRODUCTION}

29 Convergent evolution provides some of the strongest support for the theory of evolution

30 through natural selection. In the case of evolutionary convergence, organisms that may have very

31 different evolutionary history (as measured phylogenetically), are driven by similar selective

32 pressures to a highly similar phenotype (Losos, 2011). These selective pressures repeatedly create

33 the same adaptive syndrome - a set of characteristics which come together to allow a specific

34 lifestyle or perform a certain task (Reich et al., 2003). In many instances in the past, convergent

35 evolutionary syndromes have confounded taxonomists, who (for example) mistakenly grouped

36 New-World and Old-World vultures (Seibold \& Helbig, 1995), all marine mammals (Foote et al.,

37 2015), and many disparate lineages of microscopic organisms (Scamardella, 1999; Palenik \&

38 Haselkorn, 1992; Gupta, 2000), into clades which ultimately proved to be paraphyletic.

39 While phenotypic features of convergent taxa will appear superficially similar, they are

40 not expected to share genomic similarity due to their evolutionary independence. Large number

41 of possible sequence combinations can result in the same protein (Storz, 2016) and potentially

42 large number of protein forms and combinations of multiple proteins that can produce the same

43 effect (Bork, Sander, \& Valencia, 1993; Doolittle, 1994), so objectively defining an evolutionary

44 syndrome using genomic data is challenging. One possible solution is to define these syndromes

45 as a set of discrete functions rather than as a set of nucleotide sequences. In this way, convergent

46 syndromes are described in the same way they have evolved - adaptively by function - and can

47 be evaluated as convergent or not based on sequence similarity. Gene Ontology (GO) coding

48 (Ashburner et al., 2000) provides an objective system by which to achieve this goal. By

49 designating numerical codes for all possible biological activities and components, ranked

50 hierarchically from general to specific, synonymy of function can easily be measured between

51 even distantly related organisms. (Throughout this text, when a discrete GO term is being

52 referenced, it will be presented in italics, whereas when functions are being referenced in the 
53 more general sense, it will be presented in plain text.) Using either experimentally determined

54 gene/protein function or sequence similarity to previously identified functions, the activities of

55 individual genes are paired with specific numeric codes. Gene Ontology analyses have been used

56 in other studies to determine the functional components to a variety of traits, adaptations and

57 physiologies of interest, including adaptation to high altitudes (Qiu et al., 2012), depth tolerance

58 in deep-sea bacteria (Vezzi et al., 2005), and a number of human disorders (Ahn et al., 2003;

59 Holmans et al., 2009); however, these have identified known genes of interest and then drawn

60 conclusions of function post hoc. Rather than assigning the Gene Ontology codes first and

61 subsequently determining the functions of particular interest as has been done previously, we can

62 select functions of expected relevance a priori in order to allow for quantitative testing of their

63 adaptive relevance by comparing functions in genomes in species that exhibit a convergent

64 function. To the best of our knowledge, this is a novel approach.

\section{Plant carnivory}

66 One particularly notable convergent polyphyletic group is that of the carnivorous

67 (alternatively, insectivorous) plants. Carnivorous plant taxa were originally classified as a single

68 group due to their most striking and apparent feature, while disregarding features that would

69 typically be used to define a botanical group (e.g., floral morphology; Primack, 1987).

70 Subsequent work has demonstrated that a substantial number of phylogenetically distant plant

71 lineages have evolved a carnivorous lifestyle (Givnish, 2015), presumably in response to similar

72 selective pressures. As different lineages (or branches of the same lineage) have approached the

73 process of insect trapping and digestion in different ways, this has in some cases made the

74 defining of a plant as carnivorous or non-carnivorous difficult (Lloyd, 1934).

75 Givnish et al. (1984) defines a carnivorous plant as one that fulfills two requirements: it

76 must gain some detectable fitness benefit from animal remains in contact with its surfaces, and it 
77 must possess adaptations that facilitate the attraction, capture, or digestion of these prey animals.

78 By considering only functional attributes, this definition allows a wide range of variability in the

79 evolutionary histories and routes of adaptation of plants that are considered carnivores. Currently,

80 nearly 600 angiosperm species are recognized as carnivorous, representing as many as nine

81 independent origins across five families (Givnish, 2015). In addition, investigations into possible

82 carnivorous traits in non-vascular plants such as liverworts are ongoing (Hess, Frahm, \& Theisen,

83 2005), suggesting that evolutionary shifts in nutrient acquisition strategies are perhaps even more

84 common that currently recognized. The multiple origins and evolutionary convergence

85 demonstrated by radiations such as those in Nepenthes and Sarracenia indicate that plant

86 carnivory is not phylogenetically constrained; rather, it is likely that these plants are limited by

87 their specific nutrient economics (Bloom, Chapin, \& Mooney, 1985), which allow them to

88 outcompete more typical nutrient acquisition strategies only in specific habitats (Ellison \&

89 Gotelli, 2001; Ellison et al., 2003).

90 Carnivorous plants occupy habitat where there is little competition for sunlight. Previous

91 studies have shown that, by leaf mass, many carnivorous plants have poor photosynthetic yield

92 (Ellison \& Farnsworth, 2005; Ellison, 2006), a likely consequence of the adaptions of their leaves

93 for the capture of insect prey. Additionally, some carnivorous plants invest photosynthetic carbon

94 in the fluids or secretions utilized for prey capture. In Drosera, some 3-6\% this carbon, which

95 would otherwise be expended on reproduction or vegetative growth, is used to capture prey

96 (Adamec, 2002). As a result of these compromises, carnivorous plants only outcompete other

97 plants in habitat where the resources that they sacrifice as a consequence of the carnivorous

98 lifestyle (carbon, water, sunlight) are plentiful, while the resources they specialize in obtaining

99 (nitrogen, phosphorus) are scarce. These environments are likely to be wet and sunny, with

100 acidic, nutrient-deficient soils (Givnish et. al, 1984; Ellison and Gotelli, 2001). 
101 Carnivory-associated functions

102 The most apparent trait of carnivorous plants is their ability to break down prey items

103 using digestive enzymes. As digesting animal tissue is presumably not in the repertoire of

104 ancestral angiosperms, a question of interest is how these enzymes have evolved. In many cases,

105 genes for digestive enzymes are apparent modifications of genes utilized in resistance and

106 correspond to pre-existing pathways related to herbivores and pathogens (Schulze et al., 2012;

107 Fukushima, Fang, et al., 2017) or other processes present in most plants. Examples of such

108 enzymes include chitinases, which were modified from anti-fungal and insect herbivore

109 deterrence enzymes (Hatano \& Hamada, 2008; Renner \& Specht, 2012), proteases, likely derived

110 from those involved in bacterial resistance (Mithöfer, 2011), and lipases, which are involved in

111 metabolizing stored energy (Seth et al., 2014). Furthermore, it appears that enzymes with similar

112 functions have evolved convergently in taxa with independent carnivorous origins (Fukushima,

113 Fang, et al., 2017), suggesting that it may not be difficult to evolve into the carnivorous niche.

114 However, digestive enzymes may also be obtained through symbiotic interactions with micro-

115 (Koopman et. al, 2010; Caravieri et. al, 2014) or macroorganisms (Midgley \& Stock, 1998,

116 Anderson \& Midgley, 2003), suggesting that it may be possible to evolve into the carnivorous

117 niche in part by appropriating the digestive enzymes of other species. While these plants fit

118 Givnish et al.'s (1984) definition of carnivores, these digestion-associated genes would not be

119 identifiable in the plant itself and thus would not contribute to functional overrepresentation in 120 genomic analyses.

121 In addition to modifications or resistance genes or the appropriation of enzymes produced

122 by symbionts, evidence suggests that genes used in nutrient transport are particularly important to

123 the carnivorous lifestyle. Plant genomes possess as many as 10 times the number of peptide

124 transport genes compared to other eukaryotes (Stacey et al., 2002), in addition to a wide variety

125 of transport pathways for nitrate and ammonium (Williams \& Miller, 2001). In carnivorous 
126 plants, the relative number of these pathways may be even higher. For example, in a

127 transcriptomic analysis of Utricularia gibba L., a carnivorous bladderwort with a minute genome

128 of only 80 megabases, 77 unique sequences corresponding to nitrogen transport were identified

129 (Ibarra-Laclette et al., 2011). Modification and specialization has also occurred in transporters

130 for other resources. For plants with traps involving rapid movement such as Dionaea muscipula

131 Sol. ex J.Ellis, uptake of prey nutrients may be coupled to a trap's electrical potential (Scherzer et

132 al., 2013). Modified pathways for osmolite uptake have been identified in D. muscipula, which

133 uses the HKT1-type ion channel to absorb sodium without disrupting the action potential of the

134 trap (Böhm et. al, 2016). Similar adaptations may benefit less active traps as well, as for example

135 in Sarracenia flava L. amino acid uptake is dependent on a potassium ion gradient (Plummer \&

136 Kethley, 1964).

137 Genomics represent a new approach to investigate the evolution of novel organismal

138 function. While the origin of novel biological functions and their role in adaptation to new

139 habitats and ecological niches has been an important topic in evolutionary biology since the

140 inception of the field (Darwin \& Darwin, 1897), we now know that genes may be preferentially

141 duplicated and modified, a common route to increased complexity and the possibility of new

142 structures (Vandenbussche et al., 2003) and pathways (Monson, 2003). In more extreme cases, a

143 whole-genome duplication event precedes an episode of major adaptive change (Soltis et al.,

144 2009), leaving a lineage with thousands of redundant additional genes on which evolutionary

145 processes can act. Gene copies with adaptive value are preferentially retained, while others are

146 silenced and eventually lost (Adams \& Wendel, 2005). If this general pattern is true of the genes

147 involved in plant carnivory, such genes should be identifiable on the basis of function and would

148 be expected to show a signal of overrepresentation in the genome.

149 Gene Ontology coding is an essential tool for resolving the issue of relating functionally

150 similar (but non-homologous) genes - by design, genes that differ substantially in ancestry but 
151 provide the same function should be assigned the same Gene Ontology code(s). These descriptors

152 are originally assigned based on experimental studies of specific genes in model organisms,

153 which later allows non-experimental assignment using sequence homology; however, as

154 automated annotation must be based on the content of a reference database, known biases in these

155 databases must be considered. For example, studies addressing multiple genes often focus on a

156 specific gene class within a specific organism, resulting in an overemphasis of that class in that

157 organism and its relatives; experiment-based annotations will be far more common for model

158 organisms or those of economic interest; and, as more sequences are assigned function through

159 extrapolation rather than experimentation, those assignments can be further propagated,

160 progressively increasing the distance from the original experimental basis (Altenhoff et al., 2012;

161 Thomas et al., 2012). In particular, due to these biases and methods of accurately matching

162 samples to references, there is concern that functional divergence may be missed in cases where

163 divergent sequences remain similar, or conversely, that erroneous function may be assigned when

164 there is substantial divergence from the nearest-matching reference sequence. Despite this, it has

165 been previously shown that known functionally-divergent paralogs also diverged (by $32 \%$ on

166 average) in GO codes assigned by automation (Blanc \& Wolfe, 2004) and that genes typically

167 retain highly similar functions at amino acid identity levels as low as $40 \%$ (Sangar et al., 2007).

168 Thus, there is reason to believe that identifying function from sequence data should be

169 sufficiently accurate at our desired level of specificity.

170 Hypotheses

171 This study seeks to test for a functional genetic signal of evolutionary convergence at the

172 level of the genome. Specifically, it seeks to test whether or not a convergently evolved

173 functional syndrome (i.e. metabolic pathways of carnivory) will rely on the same functions across

174 lineages (as seen in Yang et al., 2015). Three possibilities will be considered. First, organisms 
175 sharing this syndrome may not be genomically distinct from others. This is possible if the

176 functional changes required for this syndrome are not substantial at the genome level (e.g.

177 changes based on slight modification of regulatory elements or alternative splicing), or if neutral

178 variation among taxa is so substantial that the changes fall within the range of normal lineages. In

179 this case, no signal should be detected differentiating experimental taxa from control samples

180 (i.e., GO codes matching to expected carnivory-associated functions are not overrepresented).

181 Second, a syndrome may require a specific set of functions at high representational levels in

182 every lineage where it arises. This would be expected if the use of certain molecular machinery

183 were unavoidable for a task, preventing evolution of the syndrome by any other pathways. In this

184 case, it would be expected that a strong signal would be detected for functions across all

185 experimental taxa (i.e., GO codes matching to expected carnivory-associated functions are

186 uniformly overrepresented across carnivorous taxa). Lastly, a syndrome may indeed make use of

187 some functions from a set list each time it arises, but not necessarily the same functions in each

188 case. This would occur where there are several ways to address the same problem. A result where

189 many of the predicted functions show strong signal, but with greatly different findings in each

190 taxon, would support this model (i.e., GO codes matching to different carnivory-associated

191 functions are overrepresented in each carnivorous taxon).

\section{MATERIALS \& METHODS}

\section{Identification of carnivory-associated functions}

194 A literature review was conducted to develop a reference set of functions previously

195 found to be associated with plant carnivory. A topic search was performed on Web of Science in

196 December, 2016 with the following parameters: ("carnivorous plant" OR "insectivorous plant")

197 AND ("gene" OR "genome" OR "transcriptome" OR "protein") AND ("digestion" OR 
198 "transport"), producing 21 results. Publications discussing specific genes (Owen, 1999; An et al., 199 2002; Scherzer et al., 2013; Böhm et al., 2016) or overviews of putatively carnivory-associated 200 genes (Ibarra-Laclette et al., 2011; Schulze et al., 2012; Rottloff et al., 2016) in sequenced 201 carnivorous plant taxa were included (details in Supplemental Table 1). From Dionaea 202 muscipula, functions of proteins identified via proteomic analysis of the trap fluid (Schulze et al., 203 2012) were listed, with the addition of genes related to transport that had been specifically 204 targeted by other studies (Owen et al., 1999; Böhm et al., 2016). Similarly, in Nepenthes, 205 proteomic analysis of trap fluid released a list of functions likely to be associated with plant 206 carnivory (Rotloff et al., 2016), with other studies assaying for a specific digestion-associated 207 enzyme and detecting transport activity via traps' glandular symplasts (An, Fukushima, \& 208 Kobayashi, 2002 and Scherzer et al., 2013, respectively). In the bladderwort Utricularia gibba L., 209 transcriptomic analysis was used to detect statistically increased expression of genes in traps and 210 leaves putatively associated with carnivory (Ibarra-Laclette et al., 2011). Gene function terms, as

211 given by these publications, were cross-referenced with the AmiGO2 Gene Ontology Database 212 (Balsa-Canto et al., 2016) and matched to discrete GO codes that accurately represent their

213 functions (Table 1). Of 54 total terms selected, 36 final GO codes were matched, with 5 terms 214 synonymized and combined with matched terms and 13 terms having no appropriate match.

\section{Taxon sampling}

216 GenBank's list of assessed plant genomes was surveyed for the inclusion of plants 217 historically considered to be carnivorous. Four were available: Cephalotus follicularis 218 (Fukushima, Fang, et al., 2017), Drosera capensis (Butts, Bierma, \& Martin, 2016), Genlisea 219 aurea (Leushkin et al., 2013), and Utricularia gibba (Lan et al., 2017). The carnivorous taxa 220 sampled represent three independent origins of plant carnivory (Genlisea and Utricularia likely 221 sharing a single origin) in three plant orders (Caryophyllales, Oxalidales, and Lamiales). They 
222 also exemplify four different strategies for prey-capture. Cephalotus is a pitcher/pitfall trap, using

223 a nectar lure, slippery rim, and downward-facing projections to guide prey into a digestive soup

224 and prevent their escape; this strategy is also seen in Nepenthes, most Sarracenia, and some

225 carnivorous bromeliads. Drosera is a sticky-trap plant, with glandular trichomes on its leaves that

226 secrete both sticky compounds to prevent prey's escape and digestive enzymes to break them

227 down; Pinguicula and Byblis also use this strategy. Genlisea is considered a lobster-pot trap,

228 where prey species are guided to a small, funnel-like opening, through which exit is impossible;

229 Sarracenia psittacina and, arguably, Darlingtonia californica employ this strategy. Lastly,

230 Utricularia gibba, an aquatic carnivorous plant, uses a number of air-filled bladders to capture

231 and digest prey. A trigger hair is stimulated as potential prey investigates the trap, releasing an air

232 bubble contained within; the resulting vacuum pulls the prey inside, and the trap closes behind

233 them. While no other carnivorous taxa possess this specific form, it does share some

234 characteristics (a fast-moving trap activated by the stimulation of a trigger hair) with Aldrovanda

235 and Dionaea muscipula. The trap characteristics, floral morphology, and overall growth form of

236 the carnivorous taxa included in this study are depicted in Figure 1.

237 Non-carnivorous plants were also surveyed in order to establish a control range of

238 "typical" flowering plants. All assessed plant genomes for which Gene Ontology-coded

239 annotations are already available were included: Arabidopsis thaliana (Swarbreck et al., 2008),

240 Boea hygrometrica (Xiao et al., 2015), Glycine soja (Kim et al., 2010; Qi et al., 2014), and Oryza

241 sativa (Ohyanagi et al., 2006). Note that one of the carnivorous taxa, Genlisea aurea, also

242 possessed GO annotations. Lastly, the genomes of the two non-carnivorous plants most closely

243 related to carnivorous taxa were included: Ocimum tenuiflorum (Upadhyay et al., 2015), closest

244 sequenced relative of Byblis, Genlisea, Pinguicula, and Utricularia; and Actinidia chinensis

245 (Swarbreck et al., 2008), closest sequenced relative of Darlingtonia, Heliamphora, Roridula, and

246 Sarracenia. Boea hygrometrica, included for its available annotations, is also within the order of 
247 Genlisea and Utricularia. The reference-range taxa selected cover five orders (Brassicales,

248 Ericales, Fabales, Lamiales, and Poales), including both Monocots and Eudicots; thus, these

249 samples can be considered a reasonable representation of the diversity and variation of

250 angiosperms as a whole (Figure 2). While pairwise sampling and analysis of related carnivorous

251 and non-carnivorous taxa would be optimal to explicitly control for phylogenetic effects, this is

252 unfortunately not possible at present due to the lack of sequenced genomes for many plant orders

253 and the scarcity of annotated plant genomes in general. However, we expect our current reference

254 sampling design, which includes both non-carnivorous representatives from several carnivore-

255 containing orders and a wide phylogenetic range of taxa overall, to somewhat mitigate this

256 potential source of bias.

257 Data processing

258 For taxa lacking GO annotation but having putative genes already identified (e.g.,

259 Cephalotus follicularis), FASTA-formatted amino acid sequence data was downloaded. The

260 remaining samples (Actinidia chinensis, Ocimum tenuiflorum, Drosera capensis, and Utricularia

261 gibba) lacked any usable annotation data. While ideally genes and gene functions are predicted

262 by in-depth transcriptomic studies, the training of species-specific gene identification models, and

263 then confirmed by individual-gene experimental studies, this is simply unfeasible for studies of

264 diverse sets of non-model taxa. Instead, predictions of genes had to be made on the simpler basis

265 of reading frame detection. Unannotated genomes were downloaded as FASTA-formatted

266 nucleotide sequence and processed with ORFFinder (Wheeler et al., 2003) using parameters: [-ml

$267450-n$ false]. These parameters were selected to identify putative genes and extract the predicted

268 amino acid sequence. While some error in gene prediction are still likely from this method,

269 parameters were set with the hope of preventing truncated or erroneously-predicted genes from

270 entering the pipeline, e.g. very short of less than 150 amino acids and those contained entirely 
271 within the reading frame of another longer gene. Amino acid sequence data was then analyzed via

272 BLAST-P on the Ohio Supercomputer (Ohio Supercomputer Center, 1987) with the following

273 parameters: [-db nr -task blastp-fast -seg yes -num_alignments 10 -max_hsps 2 -evalue 1e-3],

274 searching against the non-redundant protein sequence database (Pruitt, Tatusova, \& Maglott,

275 2007). BLAST outputs were imported into Blast2GO (Conesa et al., 2005) and matched to GO

276 codes using the automated "Mapping" function. Exported mapping results were then processed

277 via the custom "AnnotationConverter.pl" script, to convert data into a more accessible simplified

278 text format. For taxa already accompanied by GO-coded gene annotations (Arabidopsis thaliana,

279 Boea hygrometrica, Glycine soja, Oryza sativa, and Genlisea aurea), GenBank GBFF files were

280 downloaded. The custom Perl script "GBFFConverter.pl" was used to extract genes with

281 associated GO information as simplified text. Using the "Functionalizer.pl" Perl script, the

282 resulting text data was then scanned for GO codes matching to the hypothesized carnivory-

283 associated functions selected. Counts of carnivory-associated genes were weighted against total

284 number of genes for which at least one function could be assigned, with the resulting proportions

285 (count of function, per thousand genes) used for subsequent statistical analyses. This process is

286 summarized graphically in Figure 3. Putative genes that could not be assigned to any function, or

287 that were assigned functions that could not be mapped to any GO codes, were not included in

288 total gene counts or proportional weighting of data. By using a conservative E-value parameter in

289 BLAST assignment of protein functions, we hoped to filter out low-certainty annotations,

290 particularly those potentially arising from erroneously-predicted protein sequences. Following

291 this process, a data normalization step was performed to correct for differences in tendency to

292 detect certain functions in BLAST searches vs. from GenBank annotation data.

293 To correct for differences in the likelihood of assigning a given function between samples

294 accompanied by previous annotation and those coded using BLAST and mapping, Arabidopsis

295 thaliana was analyzed by both methods, with the additional data set following the nucleotide 
296 sequence data preparation steps detailed above. The raw results of BLAST-annotated data were

297 then multiplied by the quotient of the pre-annotated data results and the $A$. thaliana BLAST data

298 results to produce corrected gene representation data. These data, along with pre-annotated

299 samples that did not require correction, were used in all statistical tests; raw data were subjected

300 to the same analyses, to ensure that the magnitude of changes in results would not be extreme

301 (suggesting the need for more complex methods of error correction). The overall assessment of

302 carnivory-associated function ("Total Carnivorous" vs. "None of the Above") was recalculated

303 for each taxon from the adjusted values of each function and the total gene count ("Total").

304 Statistical significance was considered to have six levels (“NS”, “., “””, “**”, “***”, “****”);

305 number of levels changed - either increasing or decreasing - were noted. The raw values

306 used in these corrections are listed in Supplemental Table 2.

307 Statistical analyses

308 Species were divided into "carnivorous" and "non-carnivorous" groups and analyzed on

30925 criteria (24 carnivory-associated functions, plus the sum representation of all carnivory-

310 associated functions in the genome) using a series of upper-tailed t-tests. To correct for multiple

311 tests, Storey's correction, which uses a Bayesian approach to determine realistic false discovery

312 rate (FDR) for the numerous tests involved in genome-wide studies (Storey, 2003; Storey \&

313 Tibshirani, 2003; Dabney, Storey, \& Warnes, 2010) was applied, with resulting q-values used to

314 assess significance $(\alpha=0.05)$.

315 Carnivorous taxa were also tested individually, against reference normal distributions

316 created by assessing the values seen in non-carnivorous taxa. Twenty-five reference distributions

317 were used (24 functions + overall), each defined by the median and standard deviation value

318 determined for that function in the non-carnivorous reference taxa. Statistical evaluations were 
319 conducted via a series of upper-tailed Z-tests, with Storey's correction then used within each

320 series of tests (four sets of 25 tests) to account for repeat testing effects.

\section{RESULTS}

\section{Genome information}

323 A general assessment of all included genomes for genome size, total gene number, and

324 number of unique Gene Ontology codes identified (a representation of diversity of functions

325 encoded) showed largely overlapping ranges of values (Table 2). Both the largest and smallest

326 genomes analyzed were to carnivorous plants: Genlisea aurea at $43.3 \mathrm{Mb}$ and Cephalotus

327 follicularis with $1.6 \mathrm{~Gb}$ (non-carnivorous plants ranged from 119.7 $\mathrm{Mb}$ to $1.5 \mathrm{~Gb}$ ). Similar results

328 were found for number of genes encoded, ranging from 17,685 in G. aurea to 89,073 in Drosera

329 capensis (typical plants: 28,382 to 70,250 ). The largest number of unique GO codes identified

330 was found in Arabidopsis thaliana; however, this results from the utilization of A. thaliana in the

331 development of plant GO codes. The smallest number was found in Oryza sativa (1262), with the

332 largest (after A. thaliana) found in C. follicularis (4664). Interestingly, when testing for

333 relationships between these factors, no significant $(\alpha=0.05)$ associations were found between

334 genome size and gene number $\left(p=0.857, R^{2}=0.1202\right)$, genome size and number of unique GOs

$335\left(p=0.630 R^{2}=0.0909\right)$, or gene number and number of unique GOs $\left(p=0.901, R^{2}=0.1227\right)$.

336 When comparing proportion of functionally identifiable genes that could be mapped to a

337 carnivory associated function, there was little difference between carnivorous and non-

338 carnivorous taxa. The percentage of genes mapping to a carnivory associated function in

339 carnivorous taxa ranged from $3.1 \%$ to $5.0 \%$ of all function-assigned genes; in typical plants, this

340 value ranged from $2.4 \%$ to $4.3 \%$. In terms of which specific carnivory associated functions made 
341 up each plant's proportion, the representation of each function varied wildly from taxon to taxon

342 (Figure 4; Supplemental Table 3).

343 Statistical comparisons of the genomic representation of each carnivory associated

344 function in carnivorous vs. typical plants yielded two significant $(\alpha=0.05)$ results: "Alternative

345 oxidase activity" $(\mathrm{t}=3.14, \mathrm{p}=0.011, \mathrm{q}=0.047)$ and "ATP:ADP antiporter activity" $(\mathrm{t}=4.00, \mathrm{p}=$

346 4.30E-03, $\mathrm{q}=0.037)$. A third function, "phospholipase activity" $(\mathrm{t}=2.79, \mathrm{p}=0.019, \mathrm{q}=0.053)$,

347 was detected as significant before correction, but retained only marginal significance $(\alpha=0.10)$

348 after accounting for multiple tests. Detailed results of these tests are presented in Table 3. For

349 each test, statistical power reaches $50 \%(\beta=0.50)$ at an effect size of 1.06 standard deviations

350 and $95 \%(\beta=0.05)$ at an effect size of 2.12 standard deviations $(\alpha=0.05)$.

Testing of individual carnivorous taxa yielded a total of 13 significant $(\alpha=0.05)$ results

352 and an additional five marginal $(\alpha=0.10)$ results, out of 100 total tests $(4$ species $\times 25$

353 distributions). Genlisea aurea and Drosera capensis had very few functions that showed a signal

354 of genomic overrepresentation. In Genlisea aurea, only a single function, "phospholipase

355 activity" $(Z=2.76, p=2.89 E-03, q=0.054)$ result reached marginal significance. Drosera

356 capensis had one significant function: "alternative oxidase activity" $(\mathrm{Z}=3.72, \mathrm{p}=1.01 \mathrm{E}-04, \mathrm{q}=$

357 2.45E-03). Utricularia gibba and Cephalotus follicularis were found to have a substantial portion

358 of carnivory-associated functions showing strong signals of genomic overrepresentation. In $U$.

359 gibba, five functions reached statistical significance: "alternative oxidase activity" $(\mathrm{Z}=2.36, \mathrm{p}=$

$3609.17 \mathrm{E}-03, \mathrm{q}=0.025)$, "ammonium transmembrane transport" $(\mathrm{Z}=3.58, \mathrm{p}=1.74 \mathrm{E}-04, \mathrm{q}=2.09 \mathrm{E}-$

361 03), "ATPase activity" $(Z=3.19, p=7.19 \mathrm{E}-04, \mathrm{q}=4.31 \mathrm{E}-03)$, "cysteine-type peptidase activity"

$362(Z=2.00, p=0.023, q=0.046)$, "phosphatase activity" $(Z=2.65, p=4.05 E-03, q=0.016)$, and

363 "phospholipase activity" $(\mathrm{Z}=2.30, \mathrm{p}=0.011, \mathrm{q}=0.025)$. An additional three test results were

364 marginally significant: "aspartic-type peptidase activity" $(Z=1.75, p=0.040, q=0.060)$,

365 “ATP:ADP antiporter activity" $(\mathrm{Z}=1.54, \mathrm{p}=0.062, \mathrm{q}=0.083)$, and total proportion of 
366 carnivory-associated functions $(\mathrm{Z}=1.79, \mathrm{p}=0.036, \mathrm{q}=0.060)$. In $C$. follicularis, seven functions

367 reached significance: "alternative oxidase activity" $(Z=2.36, p=9.10 \mathrm{E}-03, \mathrm{q}=0.030)$, "beta-

368 galactosidase activity" $(\mathrm{Z}=4.19, \mathrm{p}=1.40 \mathrm{E}-05, \mathrm{q}=1.99 \mathrm{E}-04)$, "glutathione transferase activity"

$369(Z=2.22, p=0.13, q=0.31)$, "lipase activity" $(Z=2.14, p=0.016, q=0.033)$, "lipid transport"

$370(\mathrm{Z}=2.31, \mathrm{p}=0.010, \mathrm{q}=0.030)$, "phospholipase activity" $(\mathrm{Z}=3.50, \mathrm{p}=2.28 \mathrm{E}-04, \mathrm{q}=0.002)$,

371 and "water channel activity" $(\mathrm{Z}=3.08, \mathrm{p}=1.04 \mathrm{E}-03, \mathrm{q}=4.96 \mathrm{E}-03)$. One additional function,

372 “ATP:ADP antiporter activity” $(\mathrm{Z}=1.91, \mathrm{p}=0.028, \mathrm{q}=0.050)$, was marginally significant.

373 Detailed results of these tests are presented in Table 4. For each test, statistical power reaches

$37450 \%(\beta=0.50)$ at an effect size of 2.62 standard deviations and $95 \%(\beta=0.05)$ at an effect size

375 of 4.94 standard deviations $(\alpha=0.05)$.

376 Some changes in results of the above analyses were observed when testing with the raw

377 data sets. In analysis 1 (Supplemental Table 4), a t-test comparison of carnivorous vs. non-

378 carnivorous taxa as groups, beta-galactosidase activity, phosphatase activity, protein

379 homodimerization, thioglucosidase activity, and water channel activity were noted as

380 marginally significant when using uncorrected data; these values dropped below marginal

381 significance $(\mathrm{q}<0.10)$ when using corrected data. Phospholipase activity was identified as

382 significant $(q<0.05)$ from uncorrected data, but decreased to marginal significance after

383 correction. In analysis 2 (Supplemental Table 5), changes were as follows: Genlisea aurea: no

384 changes. Drosera capensis: ATP:ADP antiporter activity, phosopholipase activity, and

385 thioglucosidase activity declined from significant $(q<0.05)$ to NS $(q>0.10)$, while cysteine-

386 type peptidase activity declined from marginal to NS. Utricularia gibba: ammonium

387 transmembrane transport activity and ATPase activity increased from NS to * $(\mathrm{q}<0.01)$,

388 cysteine-type peptidase activity, and phospholipase activity increased from NS to significant,

389 and aspartic-type peptidase activity and total carnivorous function increased from NS to 
390 marginal; however, phosphatase activity declined from * ${ }^{*}$ to significant, and cinnamyl-

391 alcohol dehydrogenase activity, polygalactosidase activity, and protein homodimerization

392 activity declined from significant to NS. Cephalotus follicularis: beta-galactosidase activity

393 increased from NS to ** $(\mathrm{q}<0.001)$, phospholipase activity and water channel activity

394 increased from NS to * ${ }^{*}$, glutathione transferase activity increase from marginal to

395 significant, and lipase activity and lipid transferase activity increased from NS to significant;

396 heat shock protein activity decreased from ***( ${ }^{* * 0.0001)}$ to NS, ATP:ADP antiporter

397 activity declined from ** to marginal, ATPase activity and protein homodimerization activity

398 decreased from * * to NS, polygalactosidase activity declined from significant to NS, and

399 fructose bisphosphate aldolase activity declined from marginal to NS.

400 In total across all tests, $81 \%$ of results remained unchanged in designation (Table 5).

401 For those that did change, a decrease in significance was more common (10\%) than an 402 increase (8\%). Less than half of all changes ( $7 \%$ of total tests) were of more than a single 403 significance level. Thus, the analyses presented in the main text are performed using the 404 adjusted data.

DISCUSSION

The analyses presented here were designed to identify similarities in function among carnivorous plants, and we found mixed support for our hypotheses. The null hypothesis (" $\mathrm{H}_{0}$ :

408 Carnivorous plant genomes are not distinct from typical plants in functional terms") cannot be 409 rejected for 11 of the 24 functions tested. The first alternate hypothesis (" $\mathrm{H}_{1}$ : All carnivorous 410 plants contain a shared functional signal as a result of convergence") is given some support by

411 the results of statistical comparisons between carnivorous and typical plants overall, as it does 412 appear that alternative oxidase activity and ATP:ADP anti-porter activity (as well as, potentially, 
413 phospholipase activity) may be commonly overrepresented in carnivorous taxa. Our results

414 support the other alternative hypothesis (" $\mathrm{H}_{2}$ : Carnivorous plants are distinct in gene function

415 from typical plants, but this difference varies from taxon to taxon"), as seen in nine (and one

416 additional, marginally) of the 24 functions tested. In short, only a small number of functions

417 appear to be consistently over-represented in taxa sharing the syndrome of plant carnivory;

418 others, while from a predictable set, are over-represented on a taxon-to-taxon basis but in an

419 unpredictable manner. A majority of functions, even if involved in the functional syndrome

420 described, will likely not show a detectable signal, either due to high levels of variation within

421 the control group or because other methods of up-regulation (transcriptional, translational, or

422 structural) have been employed. In any case, our study suggests that plant carnivory can evolve

423 using multiple independent metabolic pathways.

424 Overall effects

425 This study sought to detect a signal of genomic overrepresentation of functions

426 researchers had previously determined were associated with carnivory in plants. The two

427 functions consistently identified as significantly overrepresented were "alternative oxidase

428 activity" and "ATP:ADP anti-porter activity". Alternative oxidase functions primarily in the

429 mitochondria, as part of the electron transport chain. It is believed to function as a "protective"

430 enzyme, to prevent over-oxidation in the mitochondria and can be activated in response to

431 oxidative stress (Day \& Wiskich, 1995). For this function to be of common importance to

432 carnivorous taxa, there are three possible explanations: (i) carnivorous plants, due to their

433 digestive function, produce larger amounts of reactive oxygen species (consistent with Chia et al.,

434 2004), requiring more alternative oxidase to counteract their negative effects; (ii) alternative

435 oxidase is encoded in a modified form, having been co-opted to perform a different function

436 outside the mitochondrion; or (iii) alternative oxidase is functioning as it would typically, but due 
437 to the similar habitat parameters of carnivorous plants, they require its effects more frequently.

438 ATP:ADP anti-porter activity has two functions: It is involved in the maintenance of cellular

439 electrical potential (due to an $\mathrm{H}+$ gradient) in the presence of free fatty acids (Vianello, Petrussa,

440 \& Macrì, 1994) and it allows exchange of cellular ATP for plastid or bacterial-symbiont ADP

441 (Greub \& Raoult, 2003). In the first case, it may be responsible for interacting with the cellular

442 proton gradient if $\mathrm{pH}$ changes substantially during digestion; in the second, it may provide aid to

443 the symbiotic bacteria that assist carnivorous plants in digestion. A third function, "phospholipase

444 activity", was marginally significant. Phospholipases are involved in signaling interactions as

445 well as in metabolism of fatty acids and in degrading cell membranes (Chapman, 1998).

446 Carnivorous plants may possess an increased need for complex signaling pathways to regulate

447 their digestive machinery, as well as a clear need to break down cell membranes to access the

448 contents of insect cells.

\section{Individual taxa}

450 In individual analyses of each carnivorous taxon, alternative oxidase was found to be

451 significant in three species and phospholipase in two species (plus one marginal). Interestingly,

452 ATP:ADP anti-porter activity overall signal was driven by marginal results in two taxa. Genlisea

453 aurea and Drosera capensis had no significant or marginal functions outside of this set (with one

454 each). In stark contrast, Utricularia gibba and Cephalotus follicularis both had large numbers of

455 significantly overrepresented carnivory associated functions. Other than alternative oxidase

456 (significant in both), phospholipase (significant in both), and ATP:ADP anti-porter activity

457 (marginal in both), the two taxa did not overlap in any of their other nine (combined) over-

458 represented functions.

459 Utricularia gibba uniquely possessed overrepresentation in ATPase activity, cysteine-type

460 peptidase activity, ammonium transmembrane transport, phosphatase activity, and aspartic-type 
461 endopeptidase activity. Phosphatase, aspartic peptidase, and cysteine peptidase, as catabolic

462 enzymes found localized to the digestive fluids of other carnivorous taxa (Schulze et al., 2012;

463 Rotloff et al., 2016), most likely have roles in direct digestive function. Ammonium

464 transmembrane transport, while required in some amount by all plants, may be more vital for

465 Utricularia, which must extract the concentrated nitrogenous products of digestion from an

466 aquatic environment. ATPase in plants is involved in regulation of endocytotic and secretory

467 processes (Dettmer et al., 2006), which would logically be involved in both the release of

468 digestive enzymes and the absorption of digested material. Utricularia gibba was the only taxon

469 studied that had even marginal significance in the total genomic proportion of carnivorous

470 functions. Also of note is the vast difference in portion of carnivory-associated functions between

$471 U$. gibba and its close relative Genlisea aurea. While both taxa have characteristically-reduced

472 genomes, G. aurea has approximately half the genome size and gene number of $U$. gibba (Table

473 2). It may be that in Genlisea, selective pressure strongly favored deletion of duplicated genes,

474 with up-regulation or modification instead occurring at the transcriptional or translational stage.

475 In Cephalotus follicularis, beta-galactosidase activity, water channel activity, glutathione

476 transferase activity, lipase activity, and lipid transferase activity were found to be uniquely

477 overrepresented. Lipase and beta-galactosidase (which breaks polysaccharide bonds) are likely to

478 have direct involvement in digestion, having also been found in the digestive fluids of other

479 carnivorous taxa (Schulze et al., 2012; Rotloff et al., 2016); lipid transferase would logically

480 accompany lipase, either to localize lipid substrates or to move the products of their

481 decomposition. As C. follicularis must transfer water to the interior of its pitchers for digestive

482 functions to be possible at all, high levels of water channel activity is also a logical finding.

483 Non-significant functions 
485 activity, fructose bisphosphate aldolase activity, heat shock protein activity, peroxidase activity, polygalactonuronase activity, protein homodimerization activity, ribonuclease activity, serine-

representation in any taxa sampled. However, due to the relatively low statistical power to detect

489 low to moderate effect sizes with the tests performed, it is possible that these effects do exist but

490 cannot be detected. Even if accepting these negative results as accurate, it is possible that these

491 functions are preferentially utilized in other ways, such as increased transcription, increased

492 protein translation, or increased protein efficiency due to changes in amino acid sequence. Any of

493 these scenarios may also explain why certain functions are overrepresented in the genomes of 494 some carnivorous taxa but not in others.

\section{CONCLUSIONS}

The findings of this study are consistent with expectations of evolutionary convergence.

497 As distant taxa converge on a similar phenotype, predictable functional convergence occurs. This

was seen in the cases where there predicted functions, gathered from past studies of carnivorous

taxa, were determined to be significantly overrepresented in the taxa sampled. However, this

effect was not seen in all functions predicted, nor were the functions showing significant

501 overrepresentation consistent across all four taxa. It is likely that, while these taxa may often

502 show strong signal in some of the functions predicted, the number of potential avenues by which

503 to reach the same practical result is too great for any prediction to hold true in all cases.

504 The degree of molecular specificity required to meet an organism's needs can also be

505 expected to play a role, with ability to predict a specific functional set increasing proportional to

506 specificity of the convergent syndrome. In carnivorous plants, a wide range of morphologies (as

507 evidenced by the taxa included in this study) have arisen to reach the same end. In other cases, 
508 there is little flexibility in how an organism can reach the needed outcome. For example,

509 organisms that rely on the mimicry of pheromones, such as orchids that imitate bee sex and alarm

510 pheromones, are far less likely to show variation in the functions required for the end-result

511 (Stökl et al., 2005; Stökl et al., 2007; Brodmann et al., 2009). Conversely, even broadly-defined,

512 frequently re-derived evolutionary syndromes may still show repeated selection for specific

513 functional codes. It has been shown that organisms experience substantial convergence of

514 microbiome even for classes as broad as "carnivore" vs. "herbivore" (Muegge et al., 2011); it is

515 reasonable to consider that this occurrence may be accompanied by host genome functional

516 convergence as well. However, to detect a signal in these broader groups, where it may be

517 difficult to assemble a manageable list of target syndrome-associated functions, much more

518 thorough sampling would likely be required.

\section{Future Directions}

520 This study is currently limited primarily by the lack of available genomic sequence data

521 for carnivorous taxa, as well as the lack of thorough Gene Ontology annotation of plant taxa in

522 general. This study's BLAST-based annotation methodology is currently impractical for

523 substantially larger taxon sampling, and even in limited taxon sets, greater accuracy is desirable.

524 As more annotated genomes, more consistently high-quality genome assemblies, and more

525 accompanying transcriptomic data sets on which to train gene prediction models become

526 available, it will be possible to more thoroughly assess this phenomenon. As more carnivorous

527 plant taxa are sequenced and annotated (Nepenthes and Dionaea are expected, as well as

528 Sarracenia by the authors), it also becomes possible to refine the reference GO set created for

529 this study, e.g. using functions implicated in previous studies in at least 3 of 10 taxa. Another

530 potential approach is to apply similar methods to a different functional syndrome. While results 
531 may differ based on the evolutionary idiosyncrasies of groups of organisms or from one specific

532 syndrome to another, the same methods could be employed.

\section{ACKNOWLEDGEMENTS}

534 We thank the members of the Carstens Lab for suggestions and feedback on the methods

535 and presentation of this study, and Abbie Zimmer, who created original illustrations for this

536 study's four carnivorous plant taxa (Figure 1). We also thank the editor and reviewers for their

537 highly constructive feedback.

\section{REFERENCES}

539

540

541

542

543

544

545

546

547

548

549

550

551

552

553

554

555

556

557

558
Adamec L. 2002. Leaf absorption of mineral nutrients in carnivorous plants stimulates root nutrient uptake. New Phytologist 155:89-100. DOI: 10.1046/j.1469-8137.2002.00441.x.

Adams KL., Wendel JF. 2005. Polyploidy and genome evolution in plants. Current Opinion in Plant Biology 8:135-141. DOI: 10.1016/J.PBI.2005.01.001.

Ahn WS., Kim K-W., Bae SM., Yoon JH., Lee JM., Namkoong SE., Kim JH., Kim CK., Lee YJ., Kim Y-W. 2003. Targeted cellular process profiling approach for uterine leiomyoma using cDNA microarray, proteomics and gene ontology analysis. International journal of experimental pathology 84:267-79. DOI: 10.1111/J.0959-9673.2003.00362.X.

An C Il., Fukusaki EI., Kobayashi A. 2002. Aspartic proteinases are expressed in pitchers of the carnivorous plant Nepenthes alata Blanco. Planta 214:661-667. DOI: $10.1007 / \mathrm{s} 004250100665$.

Anderson B., Midgley JJ. 2003. Digestive mutualism, an alternate pathway in plant carnivory. Oikos 102:221-224. DOI: 10.1034/j.1600-0706.2003.12478.x.

Ashburner M., Ball CA., Blake JA., Botstein D., Butler H., Cherry JM., Davis AP., Dolinski K., Dwight SS., Eppig JT., Harris MA., Hill DP., Issel-Tarver L., Kasarskis A., Lewis S., Matese JC., Richardson JE., Ringwald M., Rubin GM., Sherlock G. 2000. Gene Ontology: tool for the unification of biology. Nature Genetics 25:25-29. DOI: 10.1038/75556.

Balsa-Canto E., Henriques D., Gabor A., Banga JR. 2016. AMIGO2, a toolbox for dynamic modeling, optimization and control in systems biology. Bioinformatics (Oxford, England):12. DOI: 10.1093/bioinformatics/btw411. 
559

560

561

562

563

564

565

566

567

568

569

570

571

572

573

574

575

576

577

578

579

580

581

582

583

584

585

586

587

588

589

590

591

592

593

594

595

Blanc G., Wolfe KH. 2004. Functional Divergence of Duplicated Genes Formed by Polyploidy during Arabidopsis Evolution. THE PLANT CELL ONLINE 16:1679-1691. DOI: 10.1105/tpc.021410.Bloom Arnold J., Chapin Stuart F., Mooney Harold A. 1985. Resource limitation in plants- An economic analogy. Annual review of ecology and systematics 16:363-392. DOI: 10.1146/annurev.ecolsys.16.1.363.

Böhm J., Scherzer S., Krol E., Kreuzer I., Von Meyer K., Lorey C., Mueller TD., Shabala L., Monte I., Solano R., Al-Rasheid KAS., Rennenberg H., Shabala S., Neher E., Hedrich R. 2016. The venus flytrap Dionaea muscipula counts prey-induced action potentials to induce sodium uptake. Current Biology 26:286-295. DOI: 10.1016/j.cub.2015.11.057.

Bork P., Sander C., Valencia A. 1993. Convergent evolution of similar enzymatic function on different protein folds: The hexokinase, ribokinase, and galactokinase families of sugar kinases. Protein Science 2:31-40. DOI: 10.1002/pro.5560020104.

Brodmann J., Twele R., Francke W., Yi-bo L., Xi-qiang S., Ayasse M. 2009. Orchid Mimics Honey Bee Alarm Pheromone in Order to Attract Hornets for Pollination. Current Biology 19:1368-1372. DOI: 10.1016/j.cub.2009.06.067.

Butts CT., Bierma JC., Martin RW. 2016. Novel proteases from the genome of the carnivorous plant Drosera capensis: Structural prediction and comparative analysis. Proteins: Structure, Function and Bioinformatics 84:1517-1533. DOI: 10.1002/prot.25095.

Caravieri FA., Ferreira AJ., Ferreira A., Clivati D., de Miranda VFO., Araújo WL. 2014. Bacterial community associated with traps of the carnivorous plants Utricularia hydrocarpa and Genlisea filiformis. Aquatic Botany 116:8-12. DOI: 10.1016/j.aquabot.2013.12.008.

Chapman KD. 1998. Phospholipase activity during plant growth and development and in response to environmental stress. Trends in Plant Science 3:419-426. DOI: 10.1016/S1360$1385(98) 01326-0$.

Chia TF., Aung HH., Osipov AN., Goh NK., Chia LS. 2004. Carnivorous pitcher plant uses free radicals in the digestion of prey. Redox report: communications in free radical research 9:255-261. DOI: 10.1179/135100004225006029.

Conesa A., Götz S., García-Gómez JM., Terol J., Talón M., Robles M. 2005. Blast2GO: A universal annotation and visualization tool in functional genomics research. Application note. Bioinformatics 21:3674-3676. DOI: 10.1093/bioinformatics/bti610.

Dabney A., Storey JD., Warnes GR. 2010. Q-value estimation for false discovery rate control.

Darwin C., Darwin F. 1889. Insectivorous Plants.

Day D a., Wiskich JT. 1995. Regulation of alternative oxidase activity in higher plants. Journal of bioenergetics and biomembranes.

Dettmer J., Hong-Hermesdorf A., Stierhof Y-D., Schumacher K. 2006. Vacuolar H+-ATPase Activity Is Required for Endocytic and Secretory Trafficking in Arabidopsis. The Plant Cell Online 18. 
596

597

598

599

600

601

602

603

604

605

606

607

608

609

610

611

612

613

614

615

616

617

618

619

620

621

622

623

624

625

626

627

628

629

630

631

632

633

Doolittle RF. 1994. Convergent evolution: the need to be explicit. Trends in Biochemical Sciences 19:15-18. DOI: 10.1016/0968-0004(94)90167-8.

Ellison AM., Gotelli NJ., Brewer JS., Cochran-Stafira DL., Kneitel JM., Miller TE., Worley AC., Zamora R. 2003. The evolutionary ecology of carnivorous plants. In: Advances in Ecological Research Vol 33. 1-74. DOI: 10.1016/S0065-2504(03)33009-0.

Ellison AM., Gotelli NJ. 2001. Evolutionary ecology of carnivorous plants. Trends in Ecology and Evolution 16:623-629. DOI: 10.1016/S0169-5347(01)02269-8.

Foote AD., Liu Y., Thomas GWC., Vinař T., Alföldi J., Deng J., Dugan S., van Elk CE., Hunter ME., Joshi V., Khan Z., Kovar C., Lee SL., Lindblad-Toh K., Mancia A., Nielsen R., Qin X., Qu J., Raney BJ., Vijay N., Wolf JBW., Hahn MW., Muzny DM., Worley KC., Gilbert MTP., Gibbs RA. 2015. Convergent evolution of the genomes of marine mammals. Nature Genetics 47:272-275. DOI: 10.1038/ng.3198.

Fukushima K., Fang X., Alvarez-Ponce D., Cai H., Carretero-Paulet L., Chen C., Chang T-H., Farr KM., Fujita T., Hiwatashi Y., Hoshi Y., Imai T., Kasahara M., Librado P., Mao L., Mori H., Nishiyama T., Nozawa M., Pálfalvi G., Pollard ST., Rozas J., Sánchez-Gracia A., Sankoff D., Shibata TF., Shigenobu S., Sumikawa N., Uzawa T., Xie M., Zheng C., Pollock DD., Albert VA., Li S., Hasebe M. 2017. Genome of the pitcher plant Cephalotus reveals genetic changes associated with carnivory. Nature Ecology \& Evolution 1:59. DOI: 10.1038/s41559-016-0059.

Givnish TJ. 2015. New evidence on the origin of carnivorous plants. Proceedings of the National Academy of Sciences 112:10-11. DOI: 10.1073/pnas.1422278112.

Givnish TJ., Burkhardt EL., Happel RE., Weintraub JD. 1984. Carnivory in the Bromeliad Brocchinia reducta, with a Cost/Benefit Model for the General Restriction of Carnivorous Plants to Sunny, Moist, Nutrient-Poor Habitats. The American Naturalist 124:479-497. DOI: $10.1086 / 284289$.

Greub G., Raoult D. 2003. History of the ADP/ATP-translocase-encoding gene, a parasitism gene transferred from a Chlamydiales ancestor to plants 1 billion years ago. Applied and environmental microbiology 69:5530-5. DOI: 10.1128/AEM.69.9.5530-5535.2003.

Gupta RS. 2000. The natural evolutionary relationships among prokaryotes. Critical reviews in microbiology. DOI: 10.1080/10408410091154219.

Hatano N., Hamada T. 2008. Proteome analysis of pitcher fluid of the carnivorous plant Nepenthes alata. Journal of Proteome Research 7:809-816. DOI: 10.1021/pr700566d.

Hess S., Frahm J-P., Theisen I. 2005. Evidence of zoophagy in a second liverwort species, Pleurozia purpurea. The Bryologist 108:212-218. DOI: 10.1639/6.

Holmans P., Green EK., Pahwa JS., Ferreira MAR., Purcell SM., Sklar P., Owen MJ., O’Donovan MC., Craddock N. 2009. Gene Ontology Analysis of GWA Study Data Sets Provides Insights into the Biology of Bipolar Disorder. American Journal of Human Genetics 85:1324. DOI: 10.1016/j.ajhg.2009.05.011. 
634 Ibarra-Laclette E., Albert VA., Pérez-Torres CA., Zamudio-Hernández F., Ortega-Estrada M de J., 635 Herrera-Estrella A., Herrera-Estrella L. 2011. Transcriptomics and molecular evolutionary 636 rate analysis of the bladderwort (Utricularia), a carnivorous plant with a minimal genome. 637 BMC Plant Biology 11:101. DOI: 10.1186/1471-2229-11-101.

638 Kim MY., Lee S., Van K., Kim T-H., Jeong S-C., Choi I-Y., Kim D-S., Lee Y-S., Park D., Ma J., 639 Kim W-Y., Kim B-C., Park S., Lee K-A., Kim DH., Kim KH., Shin JH., Jang YE., Kim KD., Liu WX., Chaisan T., Kang YJ., Lee Y-H., Kim K-H., Moon J-K., Schmutz J., Jackson SA., Bhak J., Lee S-H. 2010. Whole-genome sequencing and intensive analysis of the undomesticated soybean (Glycine soja Sieb. and Zucc.) genome. Proceedings of the National Academy of Sciences 107:22032-22037. DOI: 10.1073/pnas.1009526107.

Koopman MM., Fuselier DM., Hird S., Carstens BC. 2010. The carnivorous pale pitcher plant harbors diverse, distinct, and time-dependent bacterial communities. Applied and Environmental Microbiology 76:1851-1860. DOI: 10.1128/AEM.02440-09.

647

Lan T., Renner T., Ibarra-Laclette E., Farr KM., Chang T-H., Cervantes-Pérez SA., Zheng C.,

Leushkin E V., Sutormin R a., Nabieva ER., Penin A a., Kondrashov AS., Logacheva MD. 2013. The miniature genome of a carnivorous plant Genlisea aurea contains a low number of genes and short non-coding sequences. BMC genomics 14:476. DOI: 10.1186/1471-216414-476.

Lloyd FE. 1934. Is Roridula a carnivorous plant? Canadian Journal of Research:780-786.

657

658

659

660

661

662

663

664

665

666

667

668

669

670

Losos JB. 2011. CONVERGENCE, ADAPTATION, AND CONSTRAINT. Evolution 65:18271840. DOI: $10.2307 / 41240779$.

Midgley JJ., Stock WD. 1998. Natural abundance of d15N confirms insectivorous habit of Roridula gorgonias, despite it having no proteolytic enzymes. Annals of Botany 82:387-388. DOI: 10.1006/anbo.1998.0684.

Mithöfer A. 2011. Carnivorous pitcher plants: Insights in an old topic. Phytochemistry 72:16781682. DOI: 10.1016/j.phytochem.2010.11.024.

Monson RK. 2003. Gene duplication, neofunctionalization, and the evolution of C4 photosynthesis. International Journal of Plant Sciences 164:S43-S54. DOI: $10.1086 / 368400$.

671 Ohio Supercomputer Center. 1987. Ohio Supercomputer Center. Columbus OH: Ohio 
673

674

675

676

677

678

679

680

681

682 683

684

685

686

687

688

689

690

691

692

693

694

695

696

697

698

699

700

701

702

703

704

705

706

707

Ohyanagi H. 2006. The Rice Annotation Project Database (RAP-DB): hub for Oryza sativa ssp. japonica genome information. Nucleic Acids Research 34:D741-D744. DOI: 10.1093/nar/gkj094.

OWEN, Jr. T. 1999. Pathways for Nutrient Transport in the Pitchers of the Carnivorous Plant Nepenthes alata. Annals of Botany 84:459-466. DOI: 10.1006/anbo.1998.0944.

Palenik B., Haselkorn R. 1992. Multiple evolutionary origins of prochlorophytes, the chlorophyll b-containing prokaryotes. Nature 355:265-267. DOI: 10.1038/355265a0.

Plummer G., Kethley J. 1964. Foliar absorption of amino acids, peptides, and other nutrients by the pitcher plant, Sarracenia flava. Botanical Gazette 125:245-260. DOI: 10.1086/336280.

Primack RB. 1987. Relationships Among Flowers, Fruits, and Seeds. Ann. Rev. Ecol. Sysl 18:409-30.

Pruitt KD., Tatusova T., Maglott DR. 2007. NCBI reference sequences (RefSeq): A curated nonredundant sequence database of genomes, transcripts and proteins. Nucleic Acids Research 35. DOI: $10.1093 /$ nar/gk1842.

Qiu Q., Zhang G., Ma T., Qian W., Wang J., Ye Z., Cao C., Hu Q., Kim J., Larkin DM., Auvil L., Capitanu B., Ma J., Lewin HA., Qian X., Lang Y., Zhou R., Wang L., Wang K., Xia J., Liao S., Pan S., Lu X., Hou H., Wang Y., Zang X., Yin Y., Ma H., Zhang J., Wang Z., Zhang Y., Zhang D., Yonezawa T., Hasegawa M., Zhong Y., Liu W., Zhang Y., Huang Z., Zhang S., Long R., Yang H., Wang J., Lenstra JA., Cooper DN., Wu Y., Wang J., Shi P., Wang J., Liu J. 2012. The yak genome and adaptation to life at high altitude. Nature Genetics 44:946-949. DOI: $10.1038 /$ ng.2343.

Rambaut A. 2009. FigTree, a graphical viewer of phylogenetic trees. Institute of Evolutionary Biology University of Edinburgh. http://tree.bio.ed.ac.uk/software/figtree/

Reich PB., Wright IJ., Cavender-Bares J., Craine JM., Oleksyn J., Westoby M., Walters MB. 2003. The Evolution of Plant Functional Variation: Traits, Spectra, and Strategies. International Journal of Plant Sciences 164:S143-S164. DOI: 10.1086/374368.

Renner T., Specht CD. 2012. Molecular and functional evolution of class I chitinases for plant carnivory in the caryophyllales. Molecular Biology and Evolution 29:2971-2985. DOI: 10.1093/molbev/mss106.

Rottloff S., Miguel S., Biteau F., Nisse E., Hammann P., Kuhn L., Chicher J., Bazile V., Gaume L., Mignard B., Hehn A., Bourgaud F. 2016. Proteome analysis of digestive fluids in Nepenthes pitchers. Annals of botany 117:479-495. DOI: 10.1093/aob/mcw001.

Sangar V., Blankenberg DJ., Altman N., Lesk AM. 2007. Quantitative sequence-function relationships in proteins based on gene ontology. BMC Bioinformatics 8:294. DOI: 10.1186/1471-2105-8-294. Scamardella JM. 1999. Not plants or animals: A brief history of 
708

709

710

711

712

713

714

715

716

717

718

719

720

721

722

723

724

725

726

727

728

729

730

731

732

733

734

735

736

737

738

739

740

741

742

743

744

745

the origin of kingdoms protozoa, protista and protoctista. International Microbiology 2:207216. DOI: $10.2436 / \mathrm{im} . v 2 \mathrm{i} 4.9219$.

Scherzer S., Krol E., Kreuzer I., Kruse J., Karl F., Von Rüden M., Escalante-Perez M., Müller T., Rennenberg H., Al-Rasheid KAS., Neher E., Hedrich R. 2013. The Dionaea muscipula ammonium channel DmAMT1 provides NH4+ uptake associated with venus flytrap's prey digestion. Current Biology 23:1649-1657. DOI: 10.1016/j.cub.2013.07.028.

Schulze WX., Sanggaard KW., Kreuzer I., Knudsen AD., Bemm F., Thøgersen IB., Bräutigam A., Thomsen LR., Schliesky S., Dyrlund TF., Escalante-Perez M., Becker D., Schultz J., Karring H., Weber A., Højrup P., Hedrich R., Enghild JJ. 2012. The Protein Composition of the Digestive Fluid from the Venus Flytrap Sheds Light on Prey Digestion Mechanisms. Molecular \& Cellular Proteomics 11:1306-1319. DOI: 10.1074/mcp.M112.021006.

Seibold I., Helbig AJ. 1995. Evolutionary history of New and Old World vultures inferred from nucleotide sequences of the mitochondrial cytochrome $\mathrm{b}$ gene. Philosophical Transactions of the Royal Society of London B 350:163-178. DOI: 10.2307/56332.

Seth S., Chakravorty D., Dubey VK., Patra S. 2014. An insight into plant lipase research Challenges encountered. Protein Expression and Purification 95:13-21. DOI: 10.1016/j.pep.2013.11.006.

Soltis DE., Albert VA., Leebens-Mack J., Bell CD., Paterson AH., Zheng C., Sankoff D., DePamphilis CW., Wall PK., Soltis PS. 2009. Polyploidy and angiosperm diversification. American Journal of Botany 96:336-348. DOI: 10.3732/ajb.0800079.

Soltis DE., Smith SA., Cellinese N., Wurdack KJ., Tank DC., Brockington SF., RefulioRodriguez NF., Walker JB., Moore MJ., Carlsward BS., Bell CD., Latvis M., Crawley S., Black C., Diouf D., Xi Z., Rushworth CA., Gitzendanner MA., Sytsma KJ., Qiu Y-L., Hilu KW., Davis CC., Sanderson MJ., Beaman RS., Olmstead RG., Judd WS., Donoghue MJ., Soltis PS. 2011. Angiosperm phylogeny: 17 genes, 640 taxa. American journal of botany 98:704-30. DOI: 10.3732/ajb.1000404.

Stacey 'Gary., Koh S., Granger C., Becker JM. 2002. Peptide transport in plants. Trends in Plant Science 7:257-263. DOI: 10.1016/S1360-1385(02)02249-5.

Stökl J., Paulus H., Dafni A., Schulz C., Francke W., Ayasse M. 2005. Pollinator attracting odour signals in sexually deceptive orchids of the Ophrys fusca group. Plant Systematics and Evolution 254:105-120. DOI: 10.1007/s00606-005-0330-8.

Stökl J., Twele R., Erdmann DH., Francke W., Ayasse M. 2007. Comparison of the flower scent of the sexually deceptive orchid Ophrys iricolor and the female sex pheromone of its pollinator Andrena morio. Chemoecology 17:231-233. DOI: 10.1007/s00049-007-0383-y.

Storey JD. 2003. The positive false discovery rate: A Bayesian interpretation and the q-value. Annals of Statistics 31:2013-2035. DOI: 10.1214/aos/1074290335.

Storey JD., Tibshirani R. 2003. Statistical significance for genomewide studies. Proceedings of the National Academy of Sciences 100:9440-9445. DOI: 10.1073/PNAS.1530509100. 
746

747

748

749

750

751

752

753

754

755

756

757

758

759

760

761

762

763

764

765

766

767

768

769

770

771

772

773

774

775

776

777

778

779

780

781

782

783

784

Storz JF. 2016. Causes of molecular convergence and parallelism in protein evolution. Nature Reviews Genetics 17:239-250. DOI: 10.1038/nrg.2016.11.

Swarbreck D., Wilks C., Lamesch P., Berardini TZ., Garcia-Hernandez M., Foerster H., Li D., Meyer T., Muller R., Ploetz L., Radenbaugh A., Singh S., Swing V., Tissier C., Zhang P., Huala E. 2008. The Arabidopsis Information Resource (TAIR): Gene structure and function annotation. Nucleic Acids Research 36. DOI: 10.1093/nar/gkm965.

Upadhyay AK., Chacko AR., Gandhimathi A., Ghosh P., Harini K., Joseph AP., Joshi AG., Karpe SD., Kaushik S., Kuravadi N., Lingu CS., Mahita J., Malarini R., Malhotra S., Malini M., Mathew OK., Mutt E., Naika M., Nitish S., Pasha SN., Raghavender US., Rajamani A., Shilpa S., Shingate PN., Singh HR., Sukhwal A., Sunitha MS., Sumathi M., Ramaswamy S., Gowda M., Sowdhamini R. 2015. Genome sequencing of herb Tulsi (Ocimum tenuiflorum) unravels key genes behind its strong medicinal properties. BMC Plant Biology 15:212. DOI: 10.1186/s12870-015-0562-x.

Vandenbussche M., Theissen G., Van de Peer Y., Gerats T. 2003. Structural diversification and neo-functionalization during floral MADS-box gene evolution by C-terminal frameshift mutations. Nucleic Acids Research 31:4401-4409. DOI: 10.1093/nar/gkg642.

Vezzi A., Campanaro S., D’Angelo M., Simonato F., Vitulo N., Lauro FM., Cestaro A., Malacrida G., Simionati B., Cannata N., Romualdi C., Bartlett DH., Valle G. 2005. Life at depth: Photobacterium profundum genome sequence and expression analysis. Science (New York, N.Y.) 307:1459-61. DOI: 10.1126/science.1103341.

Vianello A., Petrussa E., Macrì F. 1994. ATP/ADP antiporter is involved in uncoupling of plant mitochondria induced by low concentrations of palmitate. FEBS Letters 347:239-242. DOI: 10.1016/0014-5793(94)00540-0.

Wheeler DL., Church DM., Federhen S., Lash AE., Madden TL., Pontius JU., Schuler GD., Schriml LM., Sequeira E., Tatusova TA., Wagner L. 2003. Database resources of the national center for biotechnology. Nucleic Acids Research 31:28-33. DOI: 10.1093/nar/gkg033.

Williams L., Miller A. 2001. Transporters Responsible for the Uptake and Partitioning of Nitrogenous Solutes. Annu Rev Plant Physiol Plant Mol Biol 52:659-688. DOI: 10.1146/annurev.arplant.52.1.659.

Xiao L., Yang G., Zhang L., Yang X., Zhao S., Ji Z., Zhou Q., Hu M., Wang Y., Chen M., Xu Y., Jin H., Xiao X., Hu G., Bao F., Hu Y., Wan P., Li L., Deng X., Kuang T., Xiang C., Zhu J-K., Oliver MJ., He Y. 2015. The resurrection genome of Boea hygrometrica: A blueprint for survival of dehydration. Proceedings of the National Academy of Sciences 112:5833-5837. DOI: $10.1073 /$ pnas. 1505811112 .

Yang Z., Wafula EK., Honaas LA., Zhang H., Das M., Fernandez-Aparicio M., Huang K., Bandaranayake PCG., Wu B., Der JP., Clarke CR., Ralph PE., Landherr L., Altman NS., Timko MP., Yoder JI., Westwood JH., DePamphilis CW. 2015. Comparative transcriptome analyses reveal core parasitism genes and suggest gene duplication and repurposing as 
785

sources of structural novelty. Molecular Biology and Evolution 32:767-790. DOI:

786 10.1093/molbev/msu343. 


\section{Figure 1}

Illustrations of the carnivorous taxa included in this study.

Floral characteristics (square inset) and trap morphology (circle inset) are shown, as well as overall growth form. Taxa shown are (A) Cephalotus follicularis, (B) Drosera capensis, (C) Genlisea aurea, and (D) Utricularia gibba. Illustrations by Abbie Zimmer, 2017, included with permission. 


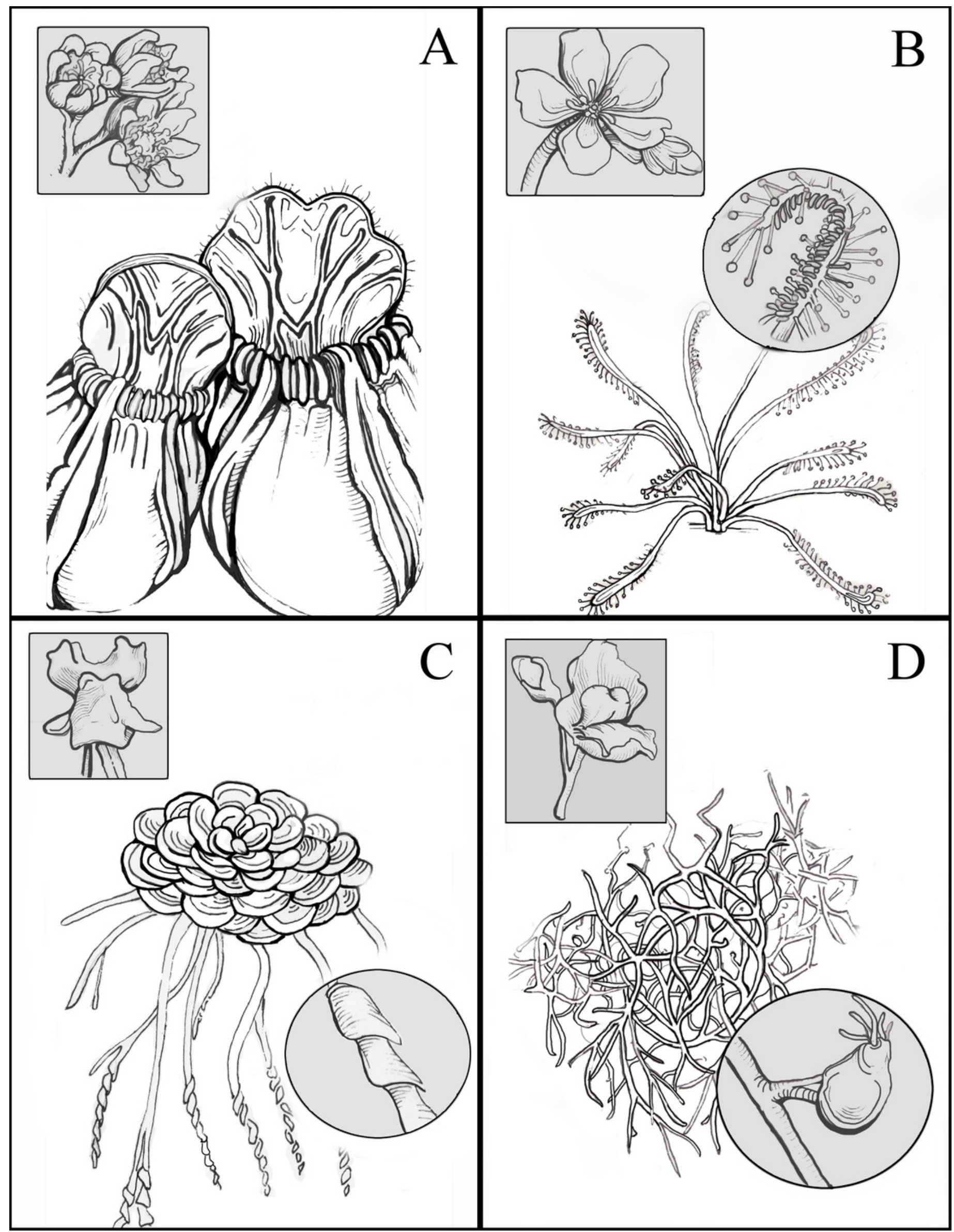




\section{Figure 2}

Radial phylogeny of all angiosperms, indicating the position of taxa relevant to this study.

White-filled triangles indicate monophyletic plant orders. Each bar indicates one genus. Blue indicates a typical/non-carnivorous control taxon included in this study; green indicates a carnivorous taxon included in this study; orange indicates a carnivorous genus (as listed in Givnish et al., 2015) for which no genome is available. Created from tree data found in Soltis et al., 2011, visualized in FigTree (Rambaut, 2009) and manually edited in InkScape. 


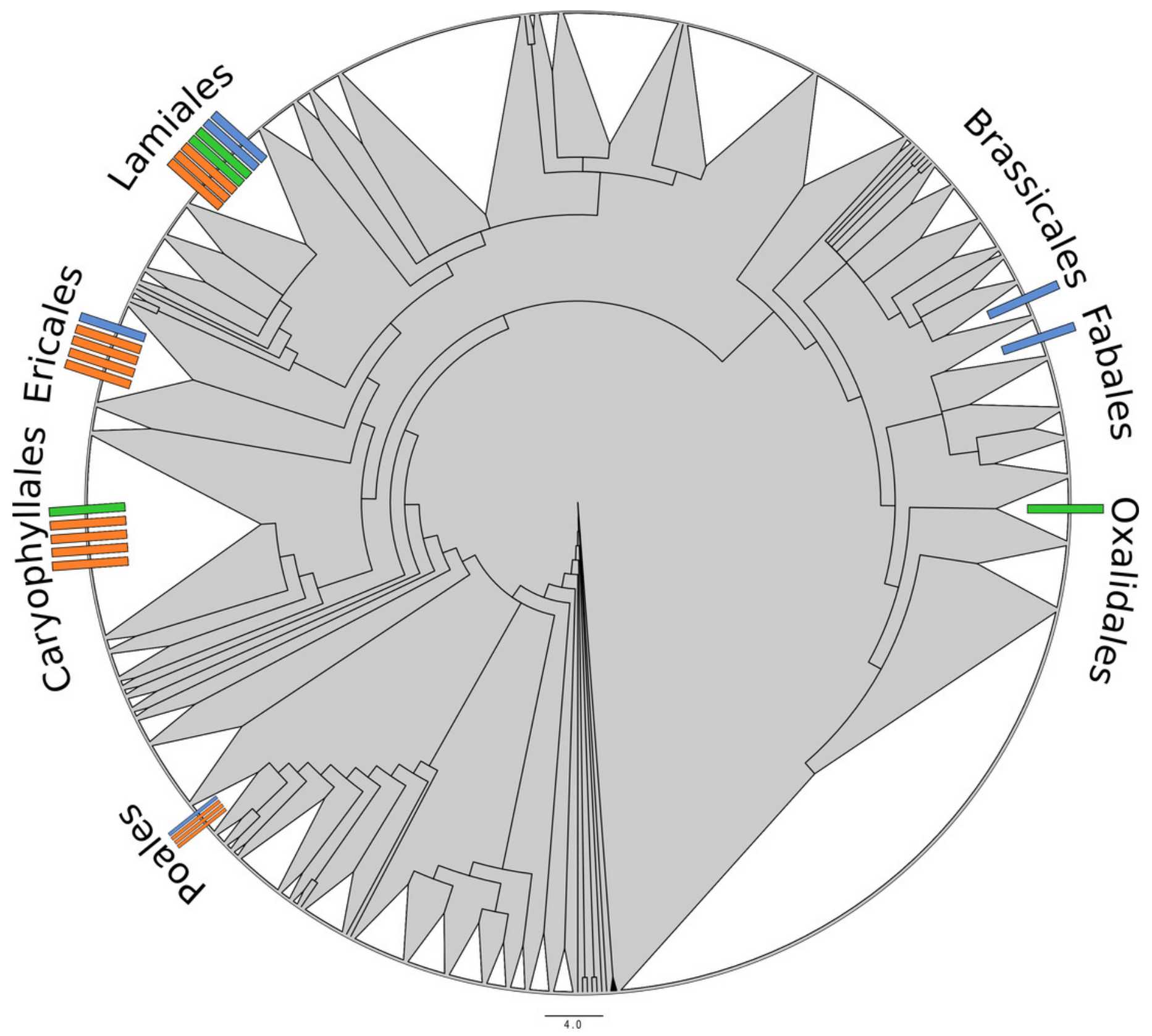




\section{Figure 3}

Flowchart detailing the preparation and processing steps to obtain gene function representation data used for subsequent statistical analyses.

Solid lines indicate processing of sampled taxa, while dashed lines indicate preparation of the reference functional set by which the taxa will be evaluated. Green boxes indicate stages utilizing custom data-processing scripts (available in Supplemental). 


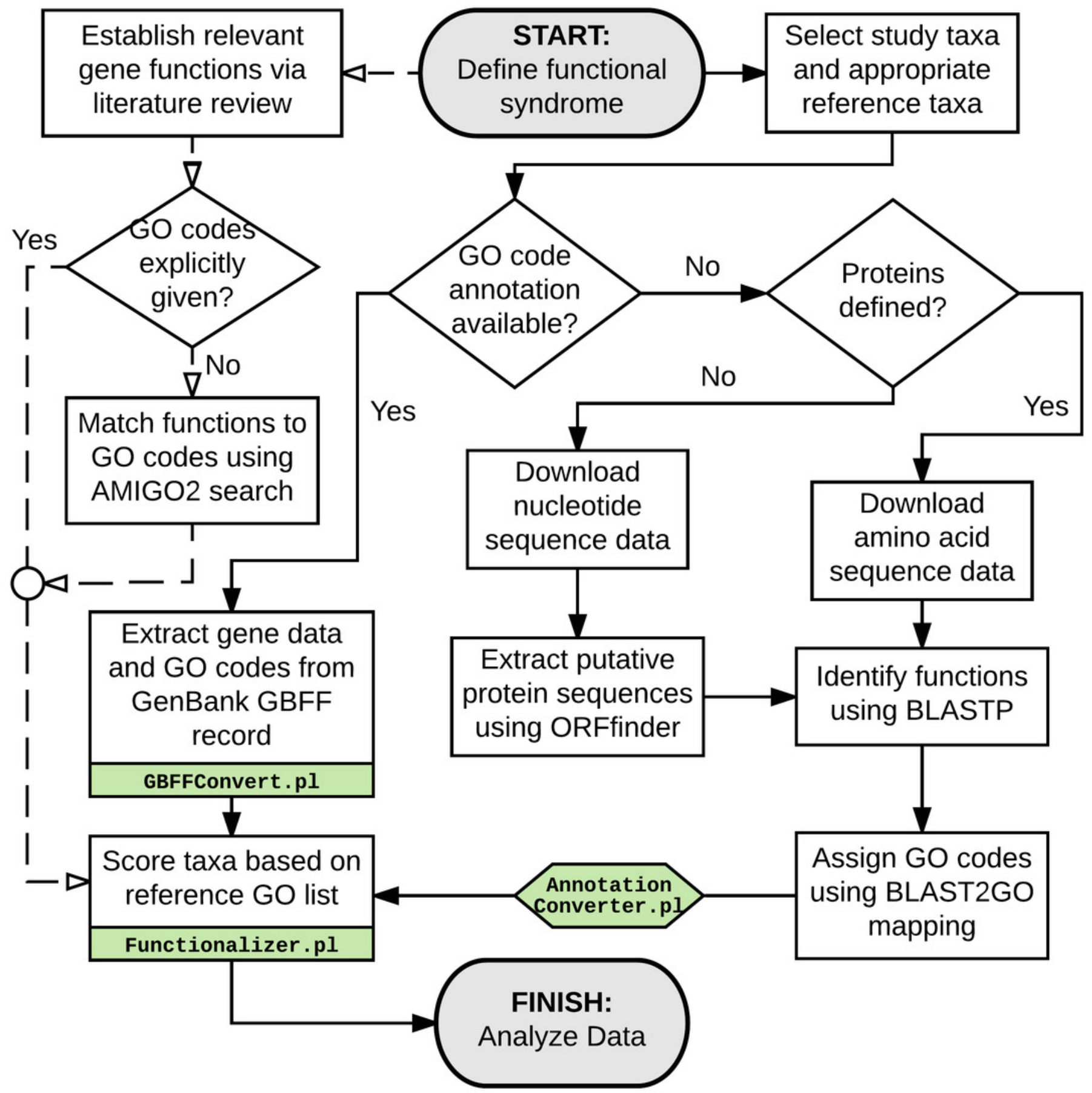




\section{Figure 4}

Chart of proportional representation of carnivorous functions vs. overall gene functions in all taxa sampled.

Pie-charts above indicate total proportion of all carnivorous functions combined (red \& percentage) vs. all other genes for which at least one function could be identified (blue). Stacked bars below indicate the proportion ascribed to each carnivory-associated function within the total, sorted from (on average) most represented (bottom) to least represented (top). The final bar, "Other", combines the rarest nine functions, which each on average represent only $0.7 \%$ of the carnivory-associated functions detected. A complete numerical view of this data is available in Supplemental Table 2.

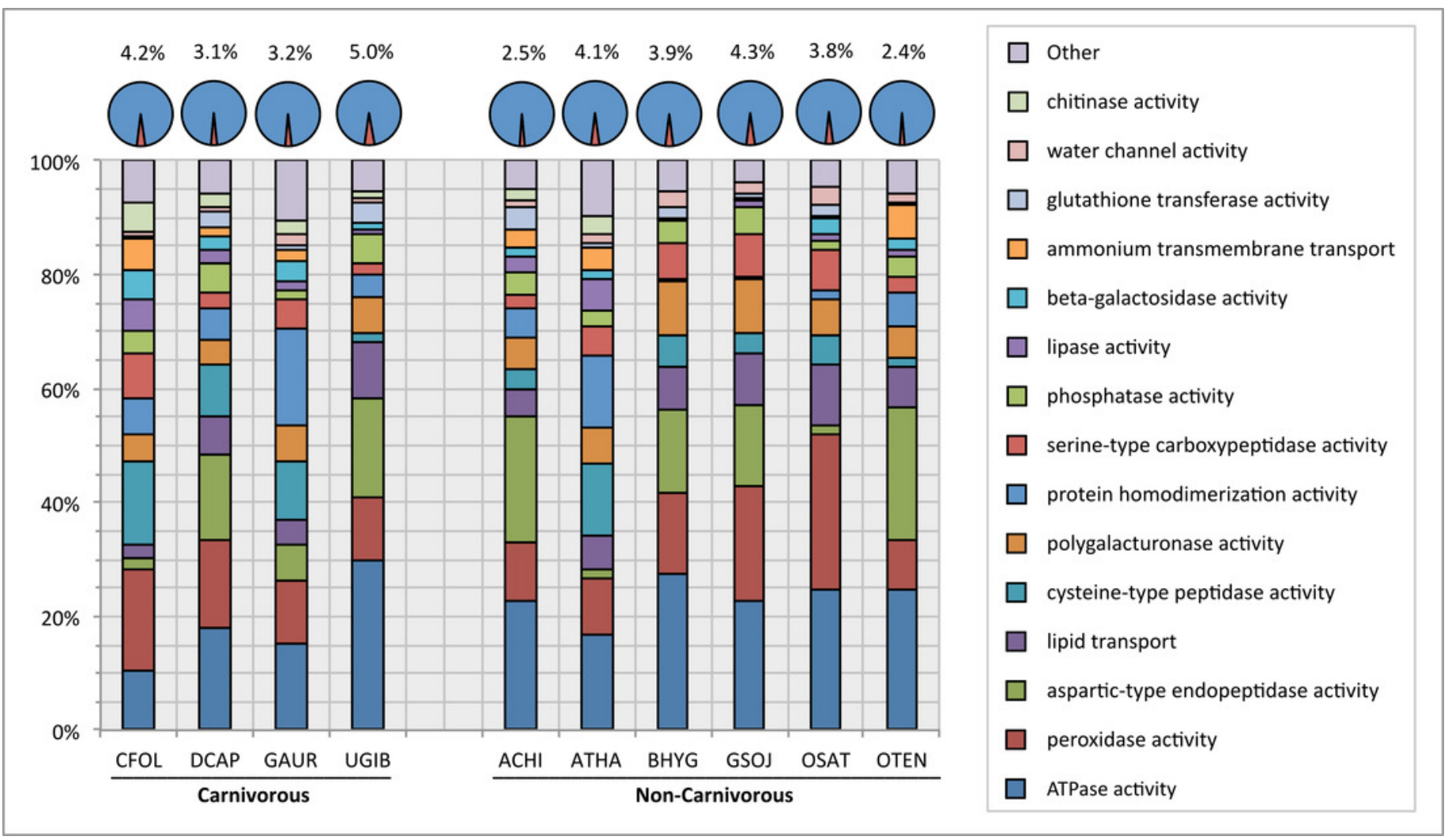




\section{Table $\mathbf{1}$ (on next page)}

Carnivory-associated functions identified via literature review.

Functions were matched to Gene Ontology terms and codes using the AmiGO2 database (Balsa-Canto et al., 2016). In cases where multiple GO codes are given, they are equivalent to or deprecated from the best-matching current term. See Supplemental Table 1 for more information. 


\begin{tabular}{|c|c|c|c|}
\hline Gene Ontology Term & GO Code & Gene Ontology Term & GO Code \\
\hline actin filament & GO:0005884 & $\begin{array}{c}\text { heat shock protein } \\
\text { activity }\end{array}$ & $\begin{array}{l}\text { GO:0042026; } \\
\text { GO:0006986; } \\
\text { GO:0034620 }\end{array}$ \\
\hline $\begin{array}{c}\text { alpha-galactosidase } \\
\text { activity }\end{array}$ & GO:0004557 & lipase activity & GO:0016298 \\
\hline $\begin{array}{c}\text { alternative oxidase } \\
\text { activity }\end{array}$ & GO:0009916 & lipid transport & GO:0006869 \\
\hline $\begin{array}{c}\text { ammonium } \\
\text { transmembrane } \\
\text { transport }\end{array}$ & $\begin{array}{l}\text { GO:0008519; } \\
\text { GO:0072488 }\end{array}$ & $\begin{array}{c}\text { methylammonium } \\
\text { channel activity }\end{array}$ & GO:0015264 \\
\hline $\begin{array}{c}\text { aspartic-type } \\
\text { endopeptidase activity }\end{array}$ & GO:0004190 & peroxidase activity & GO:0004601 \\
\hline $\begin{array}{c}\text { ATP:ADP antiporter } \\
\text { activity }\end{array}$ & GO:0005471 & phosphatase activity & GO:0016791 \\
\hline ATPase activity & GO:0016887 & phospholipase activity & GO:0004620 \\
\hline $\begin{array}{c}\text { beta-galactosidase } \\
\text { activity }\end{array}$ & GO:0004565 & $\begin{array}{c}\text { polygalacturonase } \\
\text { activity }\end{array}$ & GO:0004650 \\
\hline beta-glucanase activity & GO:0052736 & $\begin{array}{c}\text { polygalacturonase } \\
\text { inhibitor activity }\end{array}$ & GO:0090353 \\
\hline chitinase activity & GO:0004568 & $\begin{array}{c}\text { protein } \\
\text { homodimerization } \\
\text { activity }\end{array}$ & GO:0042803 \\
\hline $\begin{array}{c}\text { cinnamyl-alcohol } \\
\text { dehydrogenase activity }\end{array}$ & GO:0045551 & ribonuclease activity & GO:0004540 \\
\hline $\begin{array}{c}\text { cyclic-nucleotide } \\
\text { phosphodiesterase } \\
\text { activity }\end{array}$ & GO:0004112 & $\begin{array}{c}\text { serine-type } \\
\text { carboxypeptidase } \\
\text { activity }\end{array}$ & GO:0004185 \\
\hline $\begin{array}{c}\text { cysteine-type peptidase } \\
\text { activity }\end{array}$ & GO:0008234 & $\begin{array}{c}\text { sodium ion } \\
\text { transmembrane } \\
\text { transporter activity }\end{array}$ & GO:0022816 \\
\hline endonuclease complex & GO:1905348 & $\begin{array}{c}\text { superoxide dismutase } \\
\text { activity }\end{array}$ & GO:0004784 \\
\hline $\begin{array}{l}\text { formate dehydrogenase } \\
\text { complex }\end{array}$ & GO:0009326 & symplast & GO:0055044 \\
\hline $\begin{array}{c}\text { fructose-bisphosphate } \\
\text { aldolase activity }\end{array}$ & GO:0004332 & thioglucosidase activity & GO:0019137 \\
\hline glucosidase complex & GO:1902687 & water channel activity & GO:0015250 \\
\hline $\begin{array}{c}\text { glutathione transferase } \\
\text { activity }\end{array}$ & GO:0004364 & xylanase activity & GO:0097599 \\
\hline
\end{tabular}

1

2 


\section{Table 2 (on next page)}

General statistics of the plant genomes included in this study.

"Sequence (Mb)" indicates the available genome sequence in million base pairs. "\# Genes" indicates the number of putative genes identified, either as indicated in GenBank documentation or detected via ORFfinder. "\% Results" indicates the portion of genes that could be associated with at least one GO code. "GO Hits" indicates the total number of GOs matched to a gene across all genes. The number of unique codes present in this number is given as "Unique GOs". 
1

\begin{tabular}{|c|c|c|c|c|c|}
\hline & Sequence $(\mathrm{Mb})$ & \# Genes & \% Results & GO Hits & Unique GOs \\
\hline A. chinensis & 604.2 & 70,250 & $54.5 \%$ & 182,315 & 3830 \\
\hline A. thaliana & 119.7 & 48,350 & $56.3 \%$ & 173,184 & 6503 \\
\hline B. hygrometrica & 1521.3 & 47,778 & $23.2 \%$ & 76,891 & 2916 \\
\hline G. soja & 863.6 & 50,399 & $51.4 \%$ & 76,044 & 1421 \\
\hline O. sativa & 382.8 & 28,382 & $45.7 \%$ & 35,445 & 1262 \\
\hline O. tenuiflorum & 321.9 & 34,920 & $47.8 \%$ & 76,891 & 2916 \\
\hline C. folicularis & 1614.5 & 36,667 & $42.2 \%$ & 80,567 & 4664 \\
\hline D. capensis & 263.8 & 89,073 & $24.5 \%$ & 113,593 & 3723 \\
\hline G. aurea & 43.3 & 17,685 & $96.6 \%$ & 79,194 & 4883 \\
\hline U. gibba & 100.7 & 32,621 & $40.5 \%$ & 64,529 & 3276 \\
\hline
\end{tabular}

2

3 


\section{Table 3 (on next page)}

Results of statistical analyses comparing non-carnivorous plants to carnivorous plants for each of 24 carnivory-associated functions, plus the total of all functions.

" $t$ " indicates the test statistic of an upper-tailed Student's t-test. " $p$ " indicates the p-value of this test. " $q$ " indicates a corrected $p$-value accounting for multiple comparisons, using Storey's correction. Significance ("Sig.") is indicated by bolding and with "*" for $q<0.05$, “**" for $q<0.01$, and "*** for $q<0.001$. A non-bolded "." indicates marginal values $(q<$ $0.10)$, while "NS" indicates non-significance $(q>0.10)$. 
1

2

\begin{tabular}{|c|c|c|c|c|}
\hline & $\mathbf{Z}$ & $\mathbf{p}$ & $\mathbf{q}$ & Sig. \\
\hline Actin & 0.24 & 0.407 & 0.218 & NS \\
\hline AltOx & $\mathbf{3 . 1 4}$ & $\mathbf{0 . 0 1 1}$ & $\mathbf{0 . 0 4 7}$ & $*$ \\
\hline AspPep & 0.01 & 0.496 & 0.241 & NS \\
\hline ATP & -0.24 & 0.590 & 0.241 & NS \\
\hline ATP_ADP & $\mathbf{4 . 0 0}$ & $\mathbf{4 . 3 0 E - 0 3}$ & $\mathbf{0 . 0 3 7}$ & $*$ \\
\hline BGal & 1.90 & 0.062 & 0.127 & NS \\
\hline Chit & -1.82 & 0.944 & 0.324 & NS \\
\hline CinAlc & 0.39 & 0.355 & 0.218 & NS \\
\hline CystPep & -0.32 & 0.619 & 0.241 & NS \\
\hline FrucBPA & 0.66 & 0.266 & 0.217 & NS \\
\hline GlutTrans & 0.29 & 0.391 & 0.218 & NS \\
\hline H2OChan & 1.68 & 0.074 & 0.127 & NS \\
\hline HeatShock & 0.32 & 0.377 & 0.218 & NS \\
\hline Lipase & 0.53 & 0.309 & 0.218 & NS \\
\hline LipTrans & 0.94 & 0.193 & 0.217 & NS \\
\hline NHTrans & 0.64 & 0.278 & 0.217 & NS \\
\hline Perox & -0.14 & 0.552 & 0.241 & NS \\
\hline Phoslip & 2.79 & 0.019 & 0.053 &. \\
\hline Phosp & 0.77 & 0.240 & 0.217 & NS \\
\hline Polygal & -0.75 & 0.763 & 0.284 & NS \\
\hline ProtHomo & 1.27 & 0.122 & 0.174 & NS \\
\hline RiboNuc & -1.10 & 0.841 & 0.300 & NS \\
\hline SerCarPep & -0.29 & 0.608 & 0.241 & NS \\
\hline ThioGluc & -0.18 & 0.570 & 0.241 & NS \\
\hline Total & 0.62 & 0.278 & 0.217 & NS \\
\hline & & & &
\end{tabular}

3

4

5 


\section{Table 4(on next page)}

Results of statistical analyses comparing non-carnivorous plants to carnivorous plants in four sets, with each evaluating 24 carnivory-associated functions, plus the total of all functions.

"Z" indicates the test-statistic of an upper-tailed Z-test (equal to number of standard deviations from the mean). " $p$ " indicates the $p$-value of this test. " $q$ " indicates a corrected $p$ value accounting for multiple comparisons, using Storey's correction. Significance ("Sig.") is indicated by bolding and with "*" for $q<0.05$, "**" for $q<0.01$, and "*** for $q<0.001$. A non-bolded "." indicates marginal values $(q<0.10)$, while "NS" indicates non-significance ( $q$ $>0.10)$. 


\begin{tabular}{|c|c|c|c|c|c|c|c|c|c|c|c|c|c|c|c|c|}
\hline & \multicolumn{4}{|c|}{ Genlisea aurea } & \multicolumn{4}{|c|}{ Drosera capensis } & \multicolumn{4}{|c|}{ Utricularia gibba } & \multicolumn{4}{|c|}{ Cephalotus follicularis } \\
\hline & $\mathbf{Z}$ & $\mathbf{p}$ & $\mathbf{q}$ & Sig. & $\mathbf{z}$ & $\mathbf{p}$ & $q$ & Sig. & $\mathbf{Z}$ & $\mathbf{p}$ & $q$ & Sig. & $\mathbf{z}$ & $\mathbf{p}$ & $q$ & Sig. \\
\hline Actin & 0.25 & 0.403 & 0.626 & NS & -0.69 & 0.755 & 0.861 & NS & -0.06 & 0.525 & 0.351 & NS & 1.04 & 0.150 & 0.214 & NS \\
\hline AltOx & 0.75 & 0.228 & 0.416 & NS & 3.72 & $1.01 \mathrm{E}-04$ & $2.45 \mathrm{E}-03$ & $* *$ & 2.36 & 9.17E-03 & 0.025 & $*$ & 2.36 & $9.10 \mathrm{E}-03$ & 0.030 & $*$ \\
\hline AspPep & -0.74 & 0.771 & 0.674 & NS & 0.20 & 0.421 & 0.861 & NS & 1.75 & 0.040 & 0.060 & $\cdot$ & -1.17 & 0.880 & 0.544 & NS \\
\hline ATP & -1.50 & 0.933 & 0.697 & NS & -1.22 & 0.889 & 0.861 & NS & 3.19 & 7.19E-04 & 4.31E-03 & $* *$ & -1.67 & 0.952 & 0.544 & NS \\
\hline ATP_ADP & 1.52 & 0.064 & 0.238 & $N S$ & 1.71 & 0.043 & 0.523 & $N S$ & 1.54 & 0.062 & 0.083 & . & 1.91 & 0.028 & 0.050 & . \\
\hline BGal & 1.92 & 0.028 & 0.172 & NS & 0.55 & 0.291 & 0.861 & NS & 0.55 & 0.291 & 0.296 & NS & 4.19 & $1.40 \mathrm{E}-05$ & $1.99 \mathrm{E}-04$ & $* * *$ \\
\hline Chit & -0.35 & 0.637 & 0.674 & NS & -1.19 & 0.884 & 0.861 & NS & -0.70 & 0.757 & 0.392 & NS & -1.03 & 0.847 & 0.544 & NS \\
\hline CinAlc & 1.22 & 0.111 & 0.345 & NS & -0.39 & 0.650 & 0.861 & NS & 0.31 & 0.379 & 0.311 & NS & -0.29 & 0.616 & 0.482 & NS \\
\hline CystPep & -1.15 & 0.876 & 0.697 & NS & -0.55 & 0.708 & 0.861 & NS & 2.00 & 0.023 & 0.046 & * & -1.43 & 0.923 & 0.544 & NS \\
\hline FrucBPA & 1.56 & 0.059 & 0.238 & NS & -0.64 & 0.739 & 0.861 & NS & 0.75 & 0.227 & 0.273 & NS & -0.02 & 0.508 & 0.454 & NS \\
\hline GlutTrans & -0.19 & 0.577 & 0.674 & NS & -0.20 & 0.578 & 0.861 & NS & -0.90 & 0.817 & 0.392 & NS & 2.22 & 0.013 & 0.031 & $*$ \\
\hline H2OChan & 0.74 & 0.229 & 0.416 & NS & 0.65 & 0.259 & 0.861 & NS & 0.48 & 0.314 & 0.296 & NS & 3.08 & $1.04 \mathrm{E}-03$ & 4.96E-03 & $* *$ \\
\hline HeatShock & 0.69 & 0.244 & 0.416 & NS & -0.74 & 0.771 & 0.861 & NS & -0.07 & 0.527 & 0.351 & NS & 0.83 & 0.204 & 0.224 & NS \\
\hline Lipase & -0.26 & 0.602 & 0.674 & NS & -0.02 & 0.508 & 0.861 & NS & -0.35 & 0.637 & 0.376 & NS & 2.14 & 0.016 & 0.033 & $*$ \\
\hline LipTrans & 0.69 & 0.245 & 0.416 & NS & 0.41 & 0.340 & 0.861 & NS & -0.65 & 0.741 & 0.392 & NS & 2.31 & 0.010 & 0.030 & $*$ \\
\hline NHTrans & -0.82 & 0.794 & 0.674 & NS & 0.98 & 0.163 & 0.861 & NS & 3.58 & $1.74 \mathrm{E}-04$ & 2.09E-03 & $* *$ & -0.86 & 0.806 & 0.544 & NS \\
\hline Perox & -0.59 & 0.722 & 0.674 & NS & -0.24 & 0.596 & 0.861 & NS & 0.00 & 0.499 & 0.351 & NS & 0.57 & 0.284 & 0.270 & NS \\
\hline Phoslip & 2.76 & $2.89 \mathrm{E}-03$ & 0.054 & . & 0.31 & 0.379 & 0.861 & $N S$ & 2.30 & 0.011 & 0.025 & $*$ & 3.50 & $2.28 \mathrm{E}-04$ & 0.002 & $* *$ \\
\hline Phosp & -1.35 & 0.912 & 0.697 & NS & 0.69 & 0.244 & 0.861 & NS & 2.65 & 4.05E-03 & 0.016 & $*$ & 0.83 & 0.203 & 0.224 & NS \\
\hline Polygal & -0.46 & 0.678 & 0.674 & NS & -1.13 & 0.870 & 0.861 & NS & 0.47 & 0.320 & 0.296 & NS & -0.45 & 0.674 & 0.482 & NS \\
\hline ProtHomo & 2.09 & 0.018 & 0.169 & NS & 0.11 & 0.458 & 0.861 & NS & 0.28 & 0.388 & 0.311 & NS & 0.62 & 0.269 & 0.270 & NS \\
\hline RiboNuc & -0.62 & 0.734 & 0.674 & NS & -0.42 & 0.661 & 0.861 & NS & -0.34 & 0.635 & 0.376 & NS & -0.43 & 0.668 & 0.482 & NS \\
\hline SerCarPep & -0.32 & 0.626 & 0.674 & NS & -0.92 & 0.821 & 0.861 & NS & -0.87 & 0.808 & 0.392 & NS & 1.35 & 0.089 & 0.142 & NS \\
\hline ThioGluc & 0.85 & 0.198 & 0.416 & NS & -0.41 & 0.658 & 0.861 & NS & -0.41 & 0.658 & 0.376 & NS & -0.41 & 0.658 & 0.482 & NS \\
\hline Total & -0.38 & 0.649 & 0.674 & NS & -0.56 & 0.711 & 0.861 & NS & 1.79 & 0.036 & 0.060 & . & 0.86 & 0.195 & 0.224 & NS \\
\hline
\end{tabular}

1 


\section{Table 5 (on next page)}

Effects of data adjustment on statistical significance detected in results.

Change was measured in significance levels, considering six levels: $q>0.10$ (NS), $q<0.10$ (.), $\mathrm{q}<0.05(*), \mathrm{q}<0.01(* *), \mathrm{q}<0.001(* * *), \mathrm{q}<0.0001(* * *)$. "Increase" shows cases where a result went up one or more significance levels; "Decrease" shows cases where a result went down one or more significance levels; "Change $>1$ " shows cases where a result went either up or down two or more significance levels. "Class" indicates the results based off the categorical correction seen in Supplemental Table 4 vs. main text Table 3. "Individual" indicates the total of individual comparison results as shown by Supplemental Table 5 vs. main text Table 4; species names show these comparisons for each species considered separately. "Overall" shows the total of all tests. 


\begin{tabular}{|c|c|c|c|c|}
\hline & No Change & Increase & Decrease & Change > 1 \\
\hline Class & $19(76 \%)$ & $0(0 \%)$ & $6(24 \%)$ & $0(0 \%)$ \\
\hline Individual & $83(83 \%)$ & $10(10 \%)$ & $5(5 \%)$ & $9(9 \%)$ \\
\hline C. follicularis & $17(68 \%)$ & $6(24 \%)$ & $2(8 \%)$ & $6(24 \%)$ \\
\hline D. capensis & $21(80 \%)$ & $0(0 \%)$ & $4(16 \%)$ & $2(8 \%)$ \\
\hline G. aurea & $25(100 \%)$ & $0(0 \%)$ & $0(0 \%)$ & $0(0 \%)$ \\
\hline U. gibba & $20(80 \%)$ & $4(16 \%)$ & $0(0 \%)$ & $1(4 \%)$ \\
\hline Overall & $102(82 \%)$ & $10(8 \%)$ & $12(10 \%)$ & $9(7 \%)$ \\
\hline
\end{tabular}

1 